OPEN ACCESS

Edited by:

Vincenzo Lionetti,

Sapienza - Università di Roma, Italy

Reviewed by:

Hossein Borhan

Agriculture and Agri-Food Canada,

Canada

Steven Whitham

lowa State University, USA

${ }^{*}$ Correspondence:

Xingqi Guo

xqguo@sdau.edu.cn

Specialty section:

This article was submitted to

Plant Biotic Interactions,

a section of the journal

Frontiers in Plant Science

Received: 01 February 2016

Accepted: 05 May 2016

Published: 23 May 2016

Citation:

Wang F, Wang C, Yan Y, Jia H and Guo X (2016) Overexpression of Cotton GhMPK11 Decreases

Disease Resistance through the Gibberellin Signaling Pathway in Transgenic Nicotiana benthamiana.

Front. Plant Sci. 7:689.

doi: 10.3389/fpls.2016.00689

\section{Overexpression of Cotton GhMPK11 Decreases Disease Resistance through the Gibberellin Signaling Pathway in Transgenic Nicotiana benthamiana}

\author{
Fang Wang, Chen Wang, Yan Yan, Haihong Jia and Xingqi Guo* \\ State Key Laboratory of Crop Biology, College of Life Sciences, Shandong Agricultural University, Tai'an, China
}

Many changes in development, growth, hormone activity and environmental stimuli responses are mediated by mitogen-activated protein kinase (MAPK) cascades. However, in plants, studies on MAPKs have mainly focused on MPK3, MPK4 and MPK6. Here, a novel group B MAPK gene, GhMPK11, was isolated from cotton (Gossypium hirsutum L.) and characterized. Both promoter and expression pattern analyses revealed that GhMPK11 is involved in defense responses and signaling pathways. GhMPK11 overexpression in Nicotiana benthamiana plants could increase gibberellin $3\left(G_{3}\right)$ content through the regulation of GA-related genes. Interestingly, either GhMPK11 overexpression or exogenous $\mathrm{GA}_{3}$ treatment in $N$. benthamiana plants could enhance the susceptibility of these plants to the infectious pathogens Ralstonia solanacearum and Rhizoctonia solani. Moreover, reactive oxygen species (ROS) accumulation was increased after pathogen infiltration due to the increased expression of ROS-related gene respiratory burst oxidative homologs $(R b o h B)$ and the decreased expression or activity of ROS detoxification enzymes regulated by $\mathrm{GA}_{3}$, such as superoxide dismutases (SODs), peroxidases (PODs), catalase (CAT) and glutathione S-transferase (GST). Taken together, these results suggest that GhMPK11 overexpression could enhance the susceptibility of tobacco to pathogen infection through the $\mathrm{GA}_{3}$ signaling pathway via down-regulation of ROS detoxification enzymes.

Keywords: Gossypium hirsutum L., GhMPK11, disease resistance, GA 3 , ROS

\section{INTRODUCTION}

In contrast with animals, when confronted with various environmental challenges, plants cannot escape danger because they are sessile. To adapt to different stresses, plants have evolved sophisticated signaling pathways to transduce biotic or abiotic stimuli into proper cellular responses (Xie et al., 2014). Among those pathways, mitogen-activated protein kinase (MAPK)

Abbreviations: CaMV, cauliflower mosaic virus; CAT, catalase; $\mathrm{DAB}, 3,30$-diaminobenzidine; $\mathrm{ET}$, ethylene; $\mathrm{GA}_{3}$, gibberellin 3; GAST1, GA-stimulated transcript 1; GFP, green fluorescent protein; GST, glutathione S-transferase; GUS, $\beta$-glucuronidase; JA, jasmonic acid; KO, ent-kaurene oxidase; MS, Murashige and Skoog; MV, methyl viologen; OE, overexpressing; ORF, open reading frame; qPCR, quantitative real-time PCR; NBT, nitroblue tetrazolium; POD, peroxidase; RbohB, respiratory burst oxidase homolog; ROS, reactive oxygen species; SA, salicylic acid; SOD, superoxide dismutase; WT, wild-type. 
cascades that are conserved in all eukaryotes function as a mechanism to sense invading pathogens and then transduce internal or external signals to downstream effectors, such as transcription factors.

Typical MAPK cascades contain MAPK kinase kinases (MAPKKKs), MAPK kinases (MAPKKs) and MAPKs. MAPKKKs can activate MAPKKs by phosphorylating a dualspecificity Ser/Thr or Tyr residue (Jonak et al., 2002; Rodriguez et al., 2010). Then, activated MAPKKs can phosphorylate Thr and Tyr residues in the activation loop (A-loop) of MAPKs (Xu et al., 2014). Finally, the activated MAPKs interact with downstream transcription factors and transduce signals into cellular responses typically by altering gene expression (Widmann et al., 1999; Ichimura et al., 2002). In Arabidopsis, 20 MAPKs have been identified. Based on their sequence homology and the conserved phosphorylation motifs, MAPKs can be divided into four groups: A, B, C, and D (MAPK Group, 2002). Group A-C MAPKs contain a TEY motif in their conserved domains, while group D MAPKs contain a TDY motif (Rodriguez et al., 2010; Meng and Zhang, 2013). MAPKs in groups A and B also have a conserved common docking (CD) domain (Tanoue et al., 2000).

Plant MAPK cascades are induced by numerous environmental stresses, such as wounding, drought, salinity, cold and diverse pathogens (Pitzschke et al., 2009; Rodriguez et al., 2010; Sinha et al., 2011; Rasmussen et al., 2012; Šamajová et al., 2013). Group A MAPKs have been found to be involved in environmental and hormonal responses. GhMPK6a (Gossypium hirsutum) can reduce tolerance to osmotic stress and bacterial infection and plays an important role in development (Li et al., 2013). In Arabidopsis, AtMPK3 and AtMPK6 participate in pathogen resistance and abiotic stress (Rodriguez et al., 2010; Meng and Zhang, 2013). Of the group C MAPKs, the expression level of PsMPK2 (Pisum sativum L.) is induced by wounding, JA, abscisic acid (ABA), and $\mathrm{H}_{2} \mathrm{O}_{2}$ (Ortiz-Masia et al., 2008). AtMPK1 and AtMPK2 have been reported to be involved in pathogen signaling (Dóczi et al., 2007). In addition, GhMPK7 might participate in SA-regulated broad-spectrum resistance to pathogen infection (Shi et al., 2010). AtMPK9, a group D MAPK, is involved in ABA signaling through ROS homeostasis and calcium and anion channels (Jammes et al., 2009). A recent study revealed that GhMPK17 might be involved in plant responses to high salinity, osmotic stresses and ABA signaling (Zhang et al., 2014). AtMPK4, a group B MAPK, regulates the levels of plant hormones and negatively regulates systemic acquired resistance and innate immunity in plants (Petersen et al., 2000; Brodersen et al., 2006; Brader et al., 2007; Gao et al., 2008). However, studies on other group B members are limited.

Mitogen-activated protein kinases exert their functions in association with diverse phytohormones. SA, JA and ET are well-established phytohormones involved in disease responses (Yang D.L. et al., 2008). Development-related hormones such as brassinosteroid (Nakashita et al., 2003), cytokinin (Siemens et al., 2006), auxin (Zhang et al., 2007), and ABA (Adie et al., 2007) are associated with disease resistance. The functions of these hormones in response to diseases vary, suggesting that plants might use diverse signaling pathways to manage defense responses during pathogen infection. GA signaling also functions as a stress signal similar to other phytohormones, such as ABA or SA, under adverse conditions (Achard et al., 2006; Willige et al., 2011; Gallego-Bartolomé et al., 2012; Golldack et al., 2013; Colebrook et al., 2014). However, previous studies have mainly focused on GA's function in plant resistance to drought, salinity and other abiotic stresses, and its function in disease responses has been neglected (Achard et al., 2006; Shan et al., 2007; Li et al., 2012).

Cotton (G. hirsutum) is one of the most important economic crops and serves as an important source of food, fiber, oil and biofuel (Zhang et al., 2002; Sunilkumar et al., 2006; Chen et al., 2007). Furthermore, G. hirsutum produces more than $95 \%$ of the annual cotton crop worldwide, and its research value for genome size evolution studies cannot be ignored (Grover et al., 2004). In this study, a novel group B MAPK gene, GhMPK11 from G. hirsutum, was isolated and characterized. The transcription level of GhMPK11 could be induced by various stresses, and overexpression of GhMPK11 led to a higher level of $\mathrm{GA}_{3}$ than that in control plants. Furthermore, GhMPK11 overexpression and exogenous $\mathrm{GA}_{3}$ treatment could reduce plants resistance to pathogens. All of these results suggest that GhMPK11 may increase plants susceptibility to pathogens due to a higher level of $\mathrm{GA}_{3}$ in vivo. This study increases our understanding of MAPK signaling in cotton and indicates that GA signaling may have a role in disease responses.

\section{MATERIALS AND METHODS}

\section{Plant Materials and Treatments}

Cotton (G. hirsutum L. cv lumian 22) seeds were grown in an incubator at $25 \pm 1{ }^{\circ} \mathrm{C}$ with a $16 \mathrm{~h}$ light/ $8 \mathrm{~h}$ dark cycle (light intensity of $200 \mu \mathrm{mol} \mathrm{m} \mathrm{m}^{-2} \mathrm{~s}^{-1}$; relative humidity of $60-75 \%$ ). The 7-day-old cotton seedlings were sprayed with $10 \mathrm{mM} \mathrm{H}_{2} \mathrm{O}_{2}$, $100 \mu \mathrm{M}$ ABA and $100 \mu \mathrm{M} \mathrm{GA}_{3}$. For pathogen treatment, 7-dayold cotton seedlings were inoculated with bacterial suspensions of Ralstonia solanacearum $\left(\mathrm{OD}_{600}=0.6-0.8\right)$ and conidial suspensions of Rhizoctonia solani $\left(10^{5}\right.$ conidia/mL) using the root dip method. The treated cotyledons were harvested at the appropriate times as indicated, frozen in liquid nitrogen and stored at $-70^{\circ} \mathrm{C}$ for RNA extraction. Each treatment was repeated at least twice. $N$. benthamiana seeds were surfacesterilized, planted in soil, and maintained under a $16 \mathrm{~h}$ light $/ 8 \mathrm{~h}$ dark photoperiod at $25^{\circ} \mathrm{C}$. Three to four-leaf-stage $N$. benthamiana seedlings were transplanted into pots with soil and maintained under glasshouse conditions.

\section{Cloning of the Full Length cDNA, Genomic Sequences and 5' Flanking Region of GhMPK11}

The cDNA and genomic DNA were isolated as described previously (Yu et al., 2012). Total RNA was extracted from the leaves of cotton seedlings using the CTAB method ( $\mathrm{Hu}$ and $\mathrm{Yu}, 2007)$. To obtain the internal conserved fragment of GhMPK11, primers MF and MR were designed based on 
the nucleotide sequences and amino acids that are conserved among TcMPK4 (Theobroma cacao), AtMPK11 and AtMPK4 (Arabidopsis thaliana) and NaMPK4 (Nicotiana attenuate). Then, RT-PCR was performed to clone an internal fragment of GhMPK11. Next, primers 5N,5W, 3N and $3 \mathrm{~W}$ were designed based on the GhMPK11 fragment, and then TAIL PCR was performed to amplify the $5^{\prime}$ flanking region according to Liu and Chen (2007). The primers used in this study are shown in Supplementary Table S1. All products were purified, cloned into the pEASY-T3 vector (TransGen Biotech, China), transformed into the Escherichia coli strain $\mathrm{DH} 5 \alpha$ and then sequenced. All sequencing was performed by BioSune using an ABI $3730 \mathrm{XL}$ sequencer.

\section{RNA Extraction}

Total RNA was extracted from cotton seedlings according to the CTAB method described by $\mathrm{Hu}$ and Yu (2007). Total RNA was extracted from $N$. benthamiana seedlings using TRIzol Reagent (Invitrogen, Carlsbad, CA, USA) and digested with RNasefree DNaseI (Promega, Madison, WI, USA). The first strand cDNA was synthesized using the EasyScript First-Strand cDNA Synthesis SuperMix (TransGen Biotech, Beijing, China).

\section{Expression Pattern of GhMPK11 Using Quantitative PCR}

Total RNA was extracted from all experimental samples, and the first strand cDNA was synthesized as described above. Quantitative PCR (qRT-PCR) was performed as previously described (Wang et al., 2014). All primers used are listed in Supplementary Table S1. G. hirsutum polyubiquitin (UBI) or $N$. benthamiana $\beta$-actin genes were used as the standard control. The relative expression level of GhMPK11 was analyzed using the comparative CT method $\left(2^{-\Delta \Delta C T}\right.$ method), and three replicates of each sample were analyzed. Prism 5 software (GraphPad Software, Inc.) was used to determine significant differences.

\section{Subcellular Localization of GhMPK11}

The ORF of GhMPK11 was inserted upstream of the N-terminus of the GFP gene following the CaMV35S promoter. The recombinant vector was transformed into onion epidermal cells using the particle bombardment method as described by $\mathrm{Yu}$ et al. (2012). Then, the tissues were incubated in the dark at $25^{\circ} \mathrm{C}$ for $12 \mathrm{~h}$. Nuclei were stained with $100 \mu \mathrm{g} / \mathrm{mL} 4^{\prime}, 6$ diamidino-2-phenylindole (DAPI) (Solarbio, Beijing, China) in phosphate-buffered saline for $10 \mathrm{~min}$. The 35S::GFP construct was used as a control. In addition, the two recombinant plasmids were transferred into Agrobacterium tumefaciens strain GV3101. Agrobacterium cells were harvested by centrifugation, resuspended in infiltration buffer $(10 \mathrm{mM}$ MES, $\mathrm{pH} 5.7,10$ $\mathrm{mM} \mathrm{MgCl} 2$, and $150 \mathrm{mM}$ acetosyringone) and adjusted to a final $\mathrm{OD}_{600}$ of 1.0. After the Agrobacterium mixture was incubated for $3 \mathrm{~h}$ at room temperature in the dark, it was infiltrated into the leaves of 6-week-old N. benthamiana plants with a syringe. The 35S-GFP plasmid was used as a control. Fluorescence was observed 3 to 4 days after infiltration using a confocal laser scanning microscope (LSM 510 META, ZEISS, Germany).

\section{Vector Construction and Genetic Transformation}

The vector construction and genetic transformation were performed as previously described by Yu et al. (2012). Plants transformed with pBI121-GFP were used as controls. Transformation of the tobacco plants was confirmed by PCR. The transgenic $\mathrm{T}_{2}$ lines and vector plants were used for further experiments.

\section{GA Content Measurement}

Leaves were detached from plants OE GhMPK11 or the control were grounded in liquid nitrogen, and then soaked in 95\% chromatographic methanol at $4^{\circ} \mathrm{C}$ overnight. The solution was filtered through a $0.45 \mu \mathrm{m}$ membrane, and the $\mathrm{GA}_{3}$ content was measured via Agilent 1200 rapid resolution liquid chromatography (Agilent Technologies, Waldbronn, Germany). The mobile phase was $0.4 \%(\mathrm{v} / \mathrm{v})$ acetic acid + chromatographic methanol. Chromatography was performed at $254 \mathrm{~nm}$ at $30^{\circ} \mathrm{C}$ with a flow rate of $1.0 \mathrm{~cm}^{3} \mathrm{~min}^{-1}$. The marker for $\mathrm{GA}_{3}$ was accurately weighed and dissolved in chromatographic methanol to provide serial concentrations ranging from 0.0133 to 13.3 $\mathrm{mg} / \mathrm{mL}$. The standard curve was analyzed using the peak area, and the $\mathrm{GA}_{3}$ content was calculated.

\section{DAB and NBT Staining Assays}

For DAB staining, leaves were soaked in DAB solution $(1 \mathrm{mg} / \mathrm{mL}$, $\mathrm{pH} 3.8)$ in the dark at $25^{\circ} \mathrm{C}$ for $12 \mathrm{~h}$. Then, the leaves were incubated in $95 \%$ ethanol overnight to remove the chlorophyll. For NBT staining, the leaves were soaked in NBT solution $(0.1 \mathrm{mg} / \mathrm{mL})$ in the dark for $12 \mathrm{~h}$ at $25^{\circ} \mathrm{C}$. Then, the leaves were incubated in $95 \%$ ethanol overnight to remove the chlorophyll. Seedlings treated with water were used as controls.

\section{GUS Histochemical Staining Assay}

Transgenic Arabidopsis plants harboring the ProGhMPK11::GUS construct were generated using the floral dip method. $\mathrm{T}_{2}$ progeny were used for promoter activity analyses and stained with the GUS histochemical staining buffers as previously described (Jefferson, 1987).

\section{Disease Resistance of the Transgenic Plants}

For bacterial infection, the detached leaves of 8-week-old seedlings were inoculated with suspensions of $R$. solanacearum, a Gram-negative plant pathogenic bacterium $\left(\mathrm{OD}_{600}=0.6-0.8\right)$. The bacteria were cultured in Luria-Bertani (LB) broth overnight at $37^{\circ} \mathrm{C}$, harvested by centrifugation, and resuspended in sterile tap water. For fungal infection, $R$. solani was cultured on potato dextrose agar (PDA) medium for 2 weeks at $28^{\circ} \mathrm{C}$, and the spores were then suspended in sterile tap water. $R$. solani spore suspensions $\left(10^{5}\right.$ spores $\left./ \mathrm{mL}\right)$ were infiltrated into leaves detached from 8 -week-old $\mathrm{T}_{2}$ transgenic and control seedlings using a 
needleless syringe. At least three independent experiments were performed for each pathogen.

\section{Pathogen Growth Assays}

Total RNA was extracted from each sample using TRIzol Reagent (Invitrogen, Carlsbad, CA, USA) according to the manufacturer's instructions. The abundance of the fungus ( $R$. solani) was estimated by the ITS gene copy number through qPCR using the primer pair ITS1/ITS4 (White et al., 1990). The bacterial (R. solanacearum) abundance was estimated by the 16S rRNA gene copy number through qPCR using the primer pair Eub338 and Eub518 (Rasche et al., 2011). Amplification reactions were carried out with SYBR Premix Ex Taq (TaKaRa, Japan) in a total volume of $20 \mu \mathrm{L}$. Standard curves were obtained using serial dilutions of a known copy number of plasmids containing an ITS or 16S rRNA gene fragment, and these curves were linear from $9.77 \times 10^{3}$ to $9.77 \times 10^{8}$ gene copies $/ \mu \mathrm{L}\left(R^{2}=0.998\right.$; ITS gene $)$ and gene copies $/ \mu \mathrm{L}\left(\mathrm{R}^{2}=0.998 ; 16 \mathrm{~S}\right.$ rRNA gene). All samples were analyzed in triplicate.

\section{Enzyme Activity Assays and Oxidative Stress Experiments}

For the enzyme activity assays, the leaves of transgenic and control plants were inoculated with R. solanacearum or R. solani and then tested for SOD, POD and CAT activity as previously described (Yang L. et al., 2008). Oxidative stress experiments were performed according to Lu et al. (2013) with a modification of the MV concentration.

\section{RESULTS}

\section{Isolation and Sequence Analysis of GhMPK11}

The full-length cDNA of GhMPK11 (KP901089) contained a 95-bp $5^{\prime}$ untranslated region (UTR), 40-bp $3^{\prime}$ UTR and 1098-bp ORF that encoded a 365-amino-acid protein. Multiple alignments indicated that GhMPK11 possesses a conserved TEY motif in the activation loop, 11 conserved subdomains, and a CD domain (Figure 1A). Multiple alignments also demonstrated high identities (84.18-92.78\%) with homologous sequences, including TcMPK4 from T. cacao, AtMPK11 and AtMPK4 from $A$. thaliana and NaMPK4 from $N$. attenuata. To investigate the evolutionary relationships among MAPK proteins from different species, a phylogenetic analysis based on the amino acid sequences was performed using the neighborjoining method and MEGA software version 4.1. The results demonstrated that GhMPK11 belongs to the group B MAPK family (Figure 1B).

\section{Subcellular Localization of GhMPK11}

The Plant-mPLoc program was used to predict the subcelluar localization of GhMPK11 and indicated that GhMPK11 localizes in the nucleus. However, CELL version 2 predicted that GhMPK11 primarily localizes in the cytoplasm. To investigate the localization of GhMPK11, a biolistic transformation system was used for a transient assay. Two constructs, 35S-GhMPK11::GFP and 35S-GFP (Figure 2A), were introduced individually into onion epidermal cells. As shown in Figure 2B, fluorescent signals were found in the nucleus, and DAPI staining was also detectable in the nucleus (Supplementary Figure S1). Additionally, the 35S-GhMPK11::GFP and 35S-GFP constructs were transformed individually into tobacco cells, and fluorescence signals were found in the nucleus (Figure 2C). These results suggested that GhMPK11 localizes in the nucleus.

\section{Expression Patterns of GhMPK11}

To study the effects of signaling molecules and biotic stresses on the expression of GhMPK11, 7-day-old cotton seedlings were treated with $\mathrm{H}_{2} \mathrm{O}_{2}, \mathrm{ABA}, \mathrm{GA}_{3}, R$. solanacearum and $R$. solani. GhMPK11 expression increased strongly at $8 \mathrm{~h}$ under $\mathrm{H}_{2} \mathrm{O}_{2}$ treatment (Figure 3A). ABA treatment led to a slight increase in GhMPK11 transcription levels at $1 \mathrm{~h}$ after treatment (Figure 3B), while $\mathrm{GA}_{3}$ treatment sharply enhanced the expression level of GhMPK11 at $4 \mathrm{~h}$ after treatment (Figure 3C). Following R. solanacearum treatment, the expression level of GhMPK11 was rapidly induced within $2 \mathrm{~h}$ (Figure 3D). R. solani treatment also induced the transcription of GhMPK11 at $1 \mathrm{~h}$, and then a gradual reduction was observed (Figure 3E). These results indicated that GhMPK11 could be induced by pathogens and signaling molecules.

\section{Promoter Analysis of GhMPK11}

To characterize the underlying mechanism by which GhMPK11 responds to multiple stresses, a 1309-bp fragment was cloned upstream of the transcription start site (KP901088). The PlantCARE database was used to analyze the cis-acting regulatory elements. Some putative cis-acting regulatory elements, such as the defense-responsive elements WRKY71OS and TC-rich repeats, MBSI and the GA-response element GAREAT TC-rich repeats were found in this region. Some identified cis-elements are listed in Table 1.

To analyze the promoter activity of GhMPK11, ProGhMPK 11::GUS transgenic A. thaliana plants were obtained. GUS staining results showed that with no treatment, the GUS signal was barely detectable in the leaf and root (Figures $\mathbf{4 A}$ and $\mathrm{D}$ ). However, after the plants were treated with $\mathrm{GA}_{3}$ for 3 and $12 \mathrm{~h}$, GUS activity increased in the leaves and roots over time (Figures $\mathbf{4 B}-\mathbf{E}$ and F). These data suggested that GhMPK11 is expressed in response to GA and may be involved in the GA signaling pathway.

\section{$\mathrm{GA}_{3}$ Influences the Chlorophyll Content of GhMPK11-Overexpressing Plants}

To further analyze the function of GhMPK11, transgenic GhMPK11-OE N. benthamiana plants and transgenic vector control $N$. benthamiana plants were produced. During this process, we observed an interesting phenomenon. When compared with control plants, the leaves of GhMPK11overexpressing plants (OE plants) were less green (Figure 5A). In accordance with this phenomenon, the chlorophyll content of control plants was higher than that of OE plants (Figure 5B). 


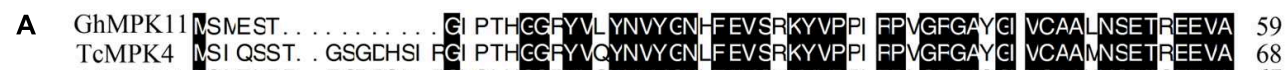

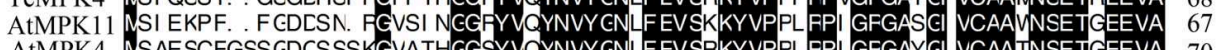

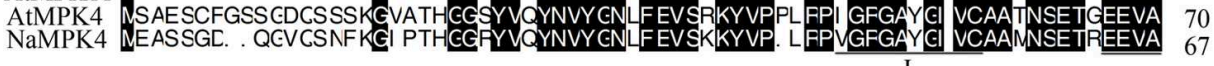

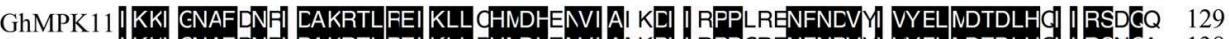

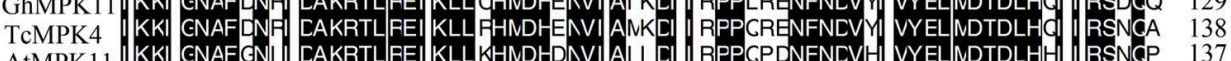

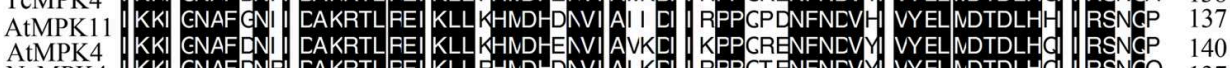

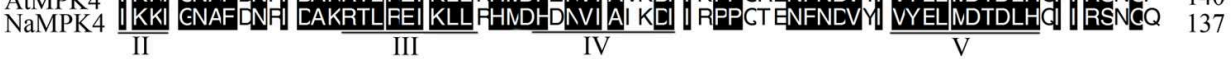

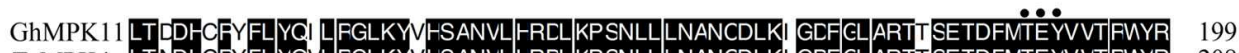
TCMPK4 LTNDFCFYFL YGULFGLKYVISSANVL FRELKKPSNLLLNANCDLKI GLFGLARTTSETDFMTEYVVTFUYR 208

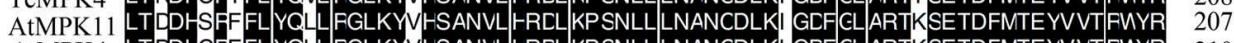

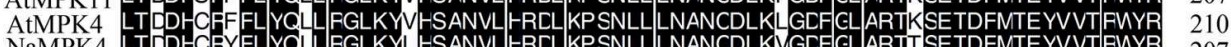

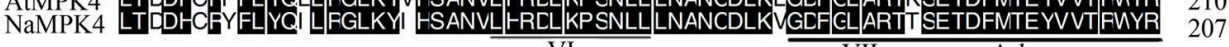

GhMPK 11 APELLLL NCSEYT AAI DI MSVGCI LCEMMTRCPLFFGFDYV/GLRLI TELI ESPDLSSLLFFLRSDNAFRYV 269 TCMPK4 APEL LL NCSEYT AAI DI USVECI L GEI MTRCPLFFGFDYVGLRLI TELI ESPDDSSL CF LRSDNAFRYV 278

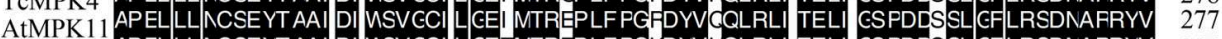
ATMPK 4 APELLL NCSEYT AAI DI USVECI L GETMTREPLFFGKDYVI-QLRLI TELI ESPDLSSLLFFLRSDNAFRYV 280

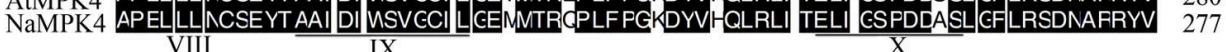

GhMPK11 FQLPCYPRCNFS SRFPMMSP GAVDLLERMLI FCPHRFI TVDEALCHPYLAFLFDI NEEFVCPFPFNFDFE 339 TCMPK4 FQLPCYPRCNFSARFPYMSPGAVDLL EKMLI I FCPHRFI TVDEALCHPYLAFL HDI NEEPVCPPPFSFDFE 348 AtMPK 11 FQLPCYPRGNFAARFPNM SVNAVDLL CKML YFCPNRFI TVDEAL CHPYLAFL| EYNEEFVCVPPFHFDFE 347 AtMPK4 FQLPCYPRONFAARFPNMSAGAVDLL EKMLYFCPSRFI TVDEALCHPYLAFLIFDI NEEFVCVFPFNFDFE 350 NaMPK 4 FQLPCYPRCOFAARFPNSSCGAVDLL EKML VFCPSRFVTVDOALCHPYLAFLHDI NEEFI CPKPFSFDFE 347

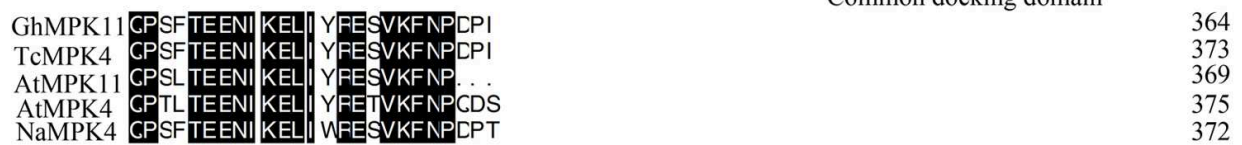

B

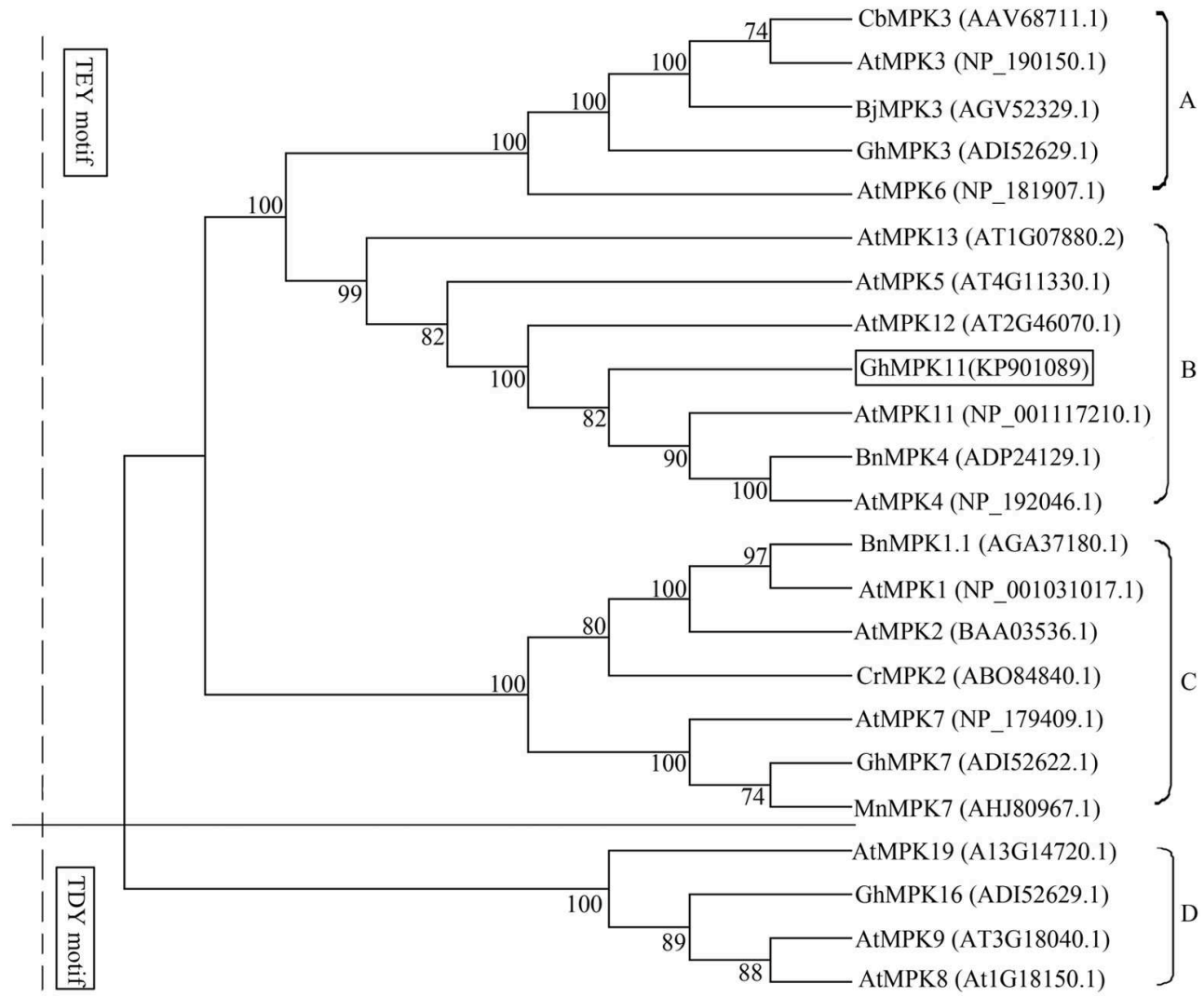

FIGURE 1 | Continued 


\section{FIGURE 1 | Continued}

Sequence and phylogenetic analyses of GhMPK11 (GenBank accession no. KP901089). (A) Multiple alignments of the GhMPK11 protein with TcMPK4 (EOX95887.1), AtMPK11 (NP_001117210.1), AtMPK4 (NP_192046.1) and NaMPK11 (ADT91692.1). Identical amino acids are shaded in black. The conserved subdomains are indicated by numerals (I-XI) at the bottom of the sequences. The activation loop (A-loop) is underlined and contains the phosphorylation motif (TEY motif) marked by a circle. The common docking domain, which is the binding site of MAPKKs and GhMPK11, is boxed. (B) Phylogenetic analysis of MAPK proteins from different species. GhMPK11 is boxed. The GenBank accession numbers are indicated in parentheses. The GenBank IDs follow the protein names.

A

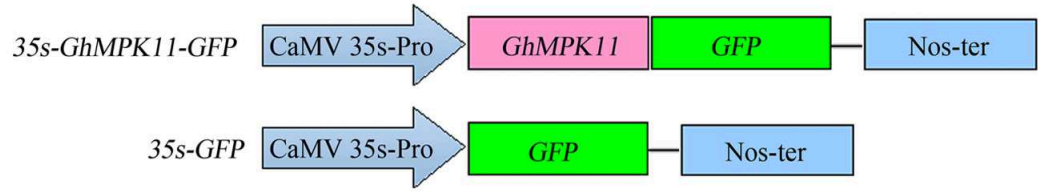

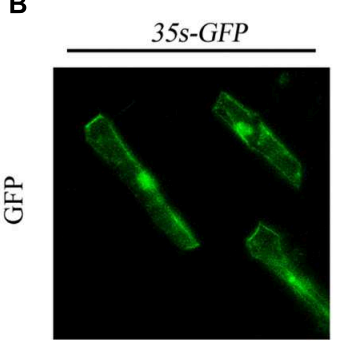
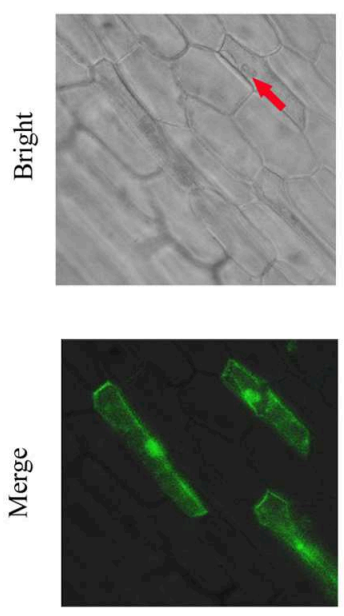

35s-GhMPK11-GFP
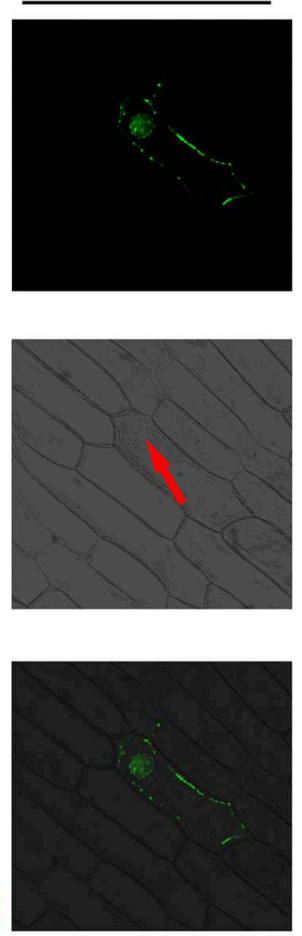

C
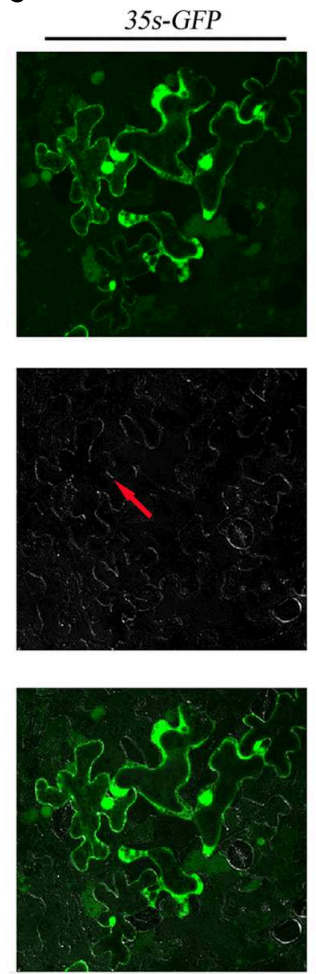
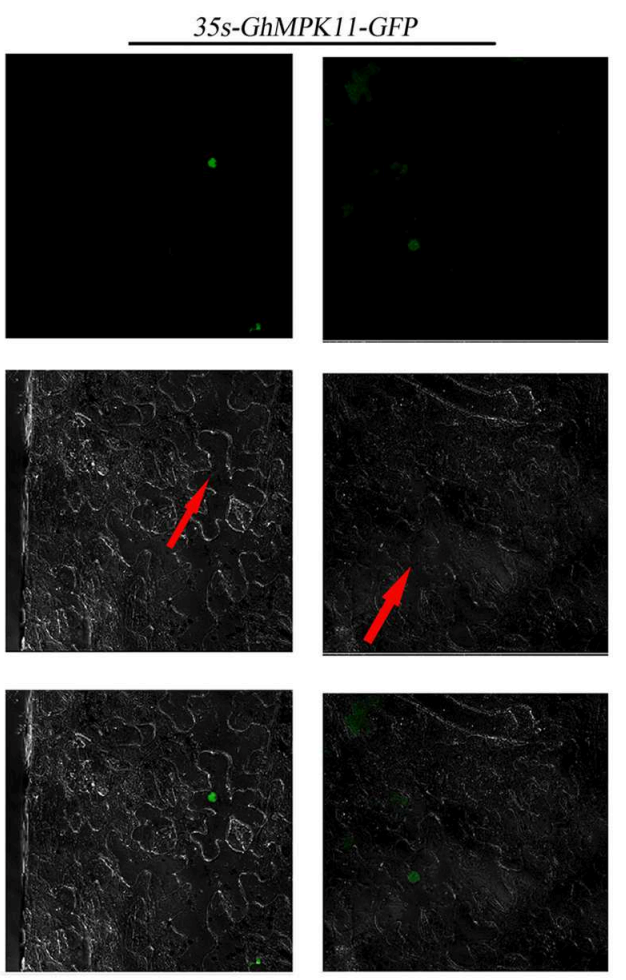

FIGURE 2 | The subcellular localization of GhMPK11 protein transiently expressed in onion epidermal cells and tobacco cells. (A) Schematic diagram of the 35S-GhMPK11-GFP fusion construct and the control 35S-GFP construct. GFP was fused to the C terminus of GhMPK11. Transient expression of the 35S-GhMPK11-GFP and 35S-GFP constructs in onion epidermal cells (B) and tobacco cells (C). Red arrows indicate the location of the nucleus. Green fluorescence was observed using a confocal microscope. Bar $=200 \mathrm{~mm}$.

Considering the sharp increase in GhMPK11 transcription under $\mathrm{GA}_{3}$ treatment and the negative effect of GA on chlorophyll synthesis (Nir et al., 2014), we analyzed the $\mathrm{GA}_{3}$ content in leaves from control and $\mathrm{OE}$ plants. Interestingly, $\mathrm{OE}$ plant leaves showed a higher level of $\mathrm{GA}_{3}$ than control plant leaves (Figure 5C). To determine whether GhMPK11 could regulate GA-related genes, the expression levels of GAST1 and KO genes were detected. The results revealed that the control plants exhibited lower expression levels of GAST1 and KO compared to OE plants (Figure 5D), which suggested that GhMPK11 regulates GA-related genes.

\section{GhMPK11-Overexpressing Plants Show Increased Susceptibility to}

\section{$R$. solanacearum and $R$. solani}

To explore the role of GhMPK11 in pathogen resistance in the transgenic tobacco plants, detached leaves from OE and control plants were infiltrated with $R$. solanacearum $\left(\mathrm{OD}_{600}=0.6-0.8\right)$ and $R$. solani $\left(10^{5}\right.$ spores $/ \mathrm{mL}$ ) resuspensions (Figures $6 \mathbf{A}, \mathbf{B}$ ). After 6 days of pathogen inoculation, OE plants showed obvious signs of chlorotic and necrotic lesions, whereas control plants did not. A burst of ROS is a common feature of defense 


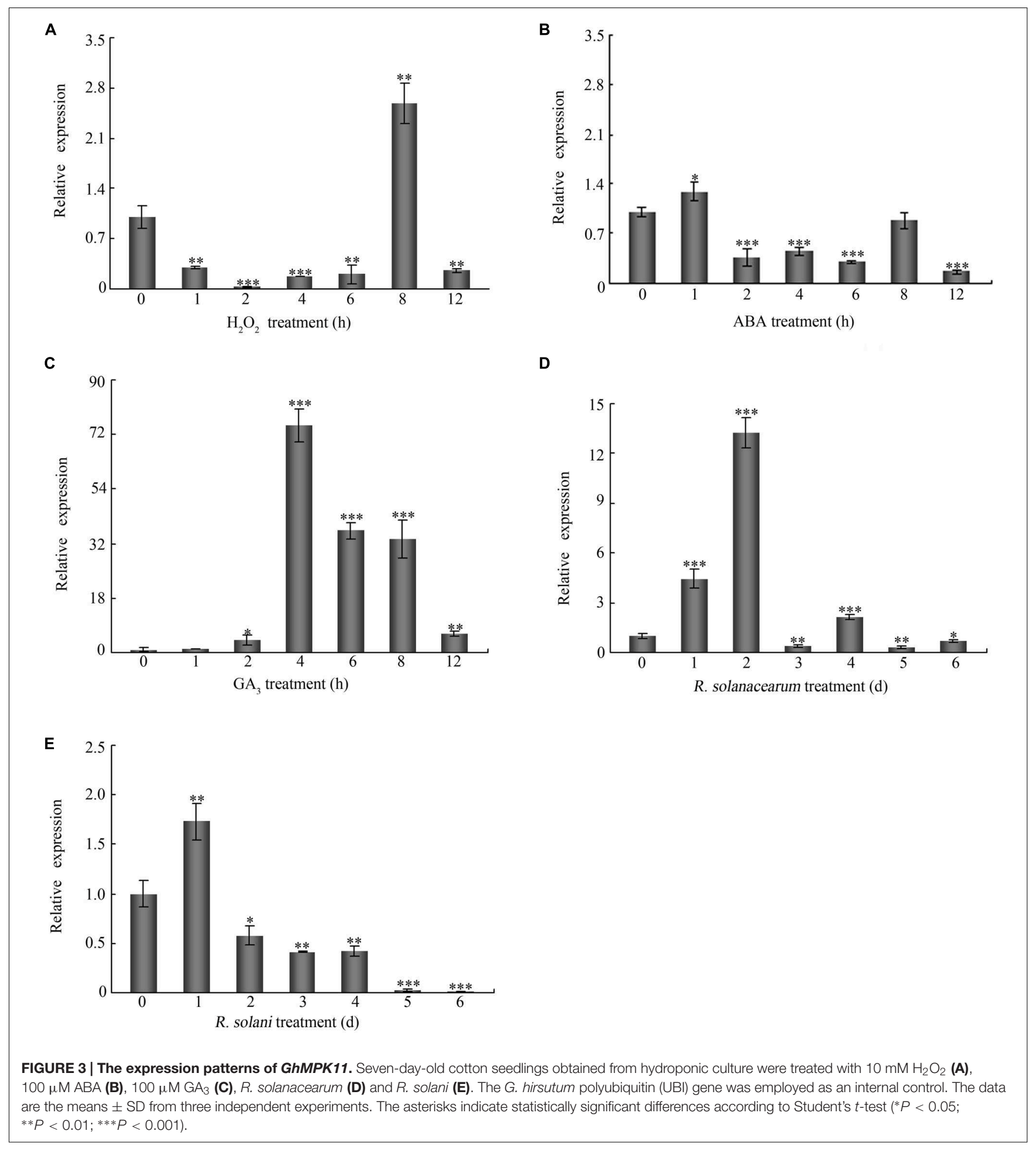

responses (Apel and Hirt, 2004; Jones and Dangl, 2006); $\mathrm{H}_{2} \mathrm{O}_{2}$ and superoxide anion $\left(\mathrm{O}_{2}^{-}\right)$are two types of ROS that can be detected by 3, 3-diaminobenzidine (DAB) and NBT staining, respectively (Thordal-Christensen et al., 1997; Fryer et al., 2002, 2003; Ren et al., 2002). Thus, staining and microscopy analyses were also performed to explain this phenomenon. The
$\mathrm{DAB}$ and NBT staining results revealed greater staining of the OE plant leaves than control plant leaves after pathogen infiltration (Figures 6A,B). Pathogen growth assays performed by qRT-PCR revealed the accumulations of $R$. solanacearum and $R$. solani particles in OE plants were higher than that in control plants after 6 days pathogen inoculation (Figures 6C,D). These 
TABLE 1 | Putative cis-acting regulatory elements in the GhMPK11 promoter.

\begin{tabular}{|c|c|c|c|}
\hline & cis-Element & Position & Sequence $\left(5^{\prime}-3^{\prime}\right)$ \\
\hline \multirow{5}{*}{$\begin{array}{l}\text { Stress } \\
\text { response } \\
\text { elements }\end{array}$} & HSE & $-1299(-)$ & AAAAAATTTC \\
\hline & LTR & $-792(-)$ & CCGAAA \\
\hline & MBSI & $-196(-)$ & aаaAaaC(G/C)GTTA \\
\hline & MBS & $-190(-),-995(+)$ & C/TAACTG \\
\hline & TC-rich repeats & $-1021(-)$ & ATTCTCTAAC \\
\hline \multirow[t]{3}{*}{ Hormones } & GAREAT & $-376(+),-1184(-)$ & TAACAAR \\
\hline & TATCCAOSAMY & $-95(+)$ & TATCCA \\
\hline & WRKY71OS & $\begin{array}{l}-401(+) \\
-1093(+) \\
-1212(+), 1206(+)\end{array}$ & TGAC/GTCA \\
\hline \multirow[t]{2}{*}{ Sugar } & WBOXHVISO1 & $\begin{array}{l}-401(+) \\
-1093(+) \\
-1212(+)\end{array}$ & TGACT \\
\hline & SREATMSD & $-94(+)$ & TTATCC \\
\hline \multirow[t]{3}{*}{$\begin{array}{l}\text { Light regulation } \\
\text { elements }\end{array}$} & $\begin{array}{l}\text { 3-AF1 binding site } \\
\text { ACE }\end{array}$ & $\begin{array}{l}-829(+) \\
-196(-),-674(+)\end{array}$ & $\begin{array}{l}\text { AAGAGATATाT } \\
\text { AAAACGTITA }\end{array}$ \\
\hline & AE-box & $-801(-)$ & AGAAACTT \\
\hline & Box4 & $-911(+),-1153(+)$ & ATTAAT \\
\hline \multirow{3}{*}{$\begin{array}{l}\text { Development- } \\
\text { related } \\
\text { elements }\end{array}$} & EIRE & $-950(+)$ & TTCGACC \\
\hline & CAAT-motif & $\begin{array}{l}-975(+),-896(+) \\
-599(+),-890(+)\end{array}$ & CAAT \\
\hline & Skn-1-motif & $-871(-),-1032(+)$ & GTCAT \\
\hline
\end{tabular}

results indicated that GhMPK11 overexpression enhanced the susceptibility of transgenic plants to pathogens and ROS.

\section{The Increased Susceptibility of Plants to Pathogen Treatment is Related to $\mathrm{GA}_{3}$ Signaling}

To evaluate which signaling pathway the GhMPK11 plants depend on, genes involved in GA, SA, and JA signaling pathways were analyzed by qRT-PCR. Total RNA was extracted from leaves before and after pathogen infiltration. After pathogen infiltration, the expression levels of GAST1 and KO, which are GA-related genes (Figures 7A,B), significantly differed, while the expression levels of the SA-related genes $P A D, P R 1 c$, and NPR 1 and of the JArelated genes $L O X$ and $J A Z 3$ only slightly differed (Figures 7CG). These findings suggested that GhMPK11 might be associated with the GA signaling pathway.

\section{Exogenous $\mathrm{GA}_{3}$ Treatment Increase the Susceptibility of Plants to $R$. solani Treatment}

To address the above hypothesis, leaves detached from control and $\mathrm{OE}$ plants were infiltrated with $R$. solani resuspension solution and divided into two groups. Group (b) served as a control [Figure $\mathbf{7 H}$ (b)], and group (a) was also treated with exogenous $\mathrm{GA}_{3}$ by placing one piece of cotton soaked in $50 \mathrm{mM}$ exogenous $\mathrm{GA}_{3}$ on the petioles [Figure $7 \mathbf{H}$ (a)]. Four days after infiltration, the leaves in group (a) showed enhanced susceptibility to $R$. solani [Figure $7 \mathbf{H}$ (a)] compared to the leaves in group (b) [Figure $7 \mathbf{H}(\mathrm{b})$ ]. Figure 7I demonstrates increased ROS accumulation in group (a) compared to group (b). Furthermore, control and OE plants showed similar responses. Taken together, these results indicated that exogenous $\mathrm{GA}_{3}$ treatment decreased the resistance of plants to $R$. solani treatment and enhanced ROS accumulation.

\section{GhMPK11 Overexpression Influences the Transcription of Defense-Related Genes and the Activity of Antioxidant Enzymes}

To further explore the underlying mechanism of pathogen sensitivity, the transcription of the ROS-related gene $R b o h B$ was analyzed. $R b o h B$ showed a higher expression level in OE plants after pathogen infiltration (Figure 8A). To maintain cellular ROS homeostasis, cells have evolved various enzymes to clear excess ROS, such as SODs, PODs, CAT and GST (Willekens et al., 1997; Apel and Hirt, 2004; Cosio and Dunand, 2009). Here, the expression levels of NtSOD, NtCAT and NtGST were measured by qRT-PCR, and all of these enzymes had higher expression levels in control plants than in OE plants (Figures 8BD) after either $R$. solanacearum or $R$. solani treatment. Similarly, after $R$. solanacearum or $R$. solani treatment, control plants showed higher activity levels of the antioxidant enzymes SOD and POD (Figures 8E,G). CAT activity was lower in OE plants compared to control plants when treated with $R$. solanacearum, while CAT activity was higher in OE plants after $R$. solani treatment (Figure 8F). All these data indicated that GhMPK11 overexpression might enhance ROS accumulation by regulating ROS-related genes and antioxidant enzymes under pathogen infiltration.

\section{GhMPK11 Overexpression Reduces the Resistance of Transgenic Plants to Oxidative Stress}

Methyl viologen is an herbicide that can cause chlorophyll degradation and cell membrane leakage through ROS production (Kurepa et al., 1998). In our study, MV was used to treat transgenic plants in order to detect the responses of GhMPK11 to oxidative stress. At the vegetable stage (8-week-old seedlings), after detached leaves were soaked in MV solution for $72 \mathrm{~h}$, leaves from transgenic plants displayed more serious bleaching or chlorosis than those from control plants (Figure 9A). Furthermore, Figure 9B shows the decreased chlorophyll content of transgenic leaves, further validating the difference in oxidative damage between the transgenic and control plants. These results suggested that GhMPK11 has a negative influence on oxidative stress responses.

\section{DISCUSSION}

Although many studies have revealed the biological function of specific MAPK proteins in plant defense responses, these studies have mainly focused on MPK3, MPK6 and MPK4, and studies of other MAPK members, especially MAPKs in cotton, are limited. In this study, a group B MAPK gene, GhMPK11, was isolated and characterized in cotton. GhMPK11 transgenic plants 


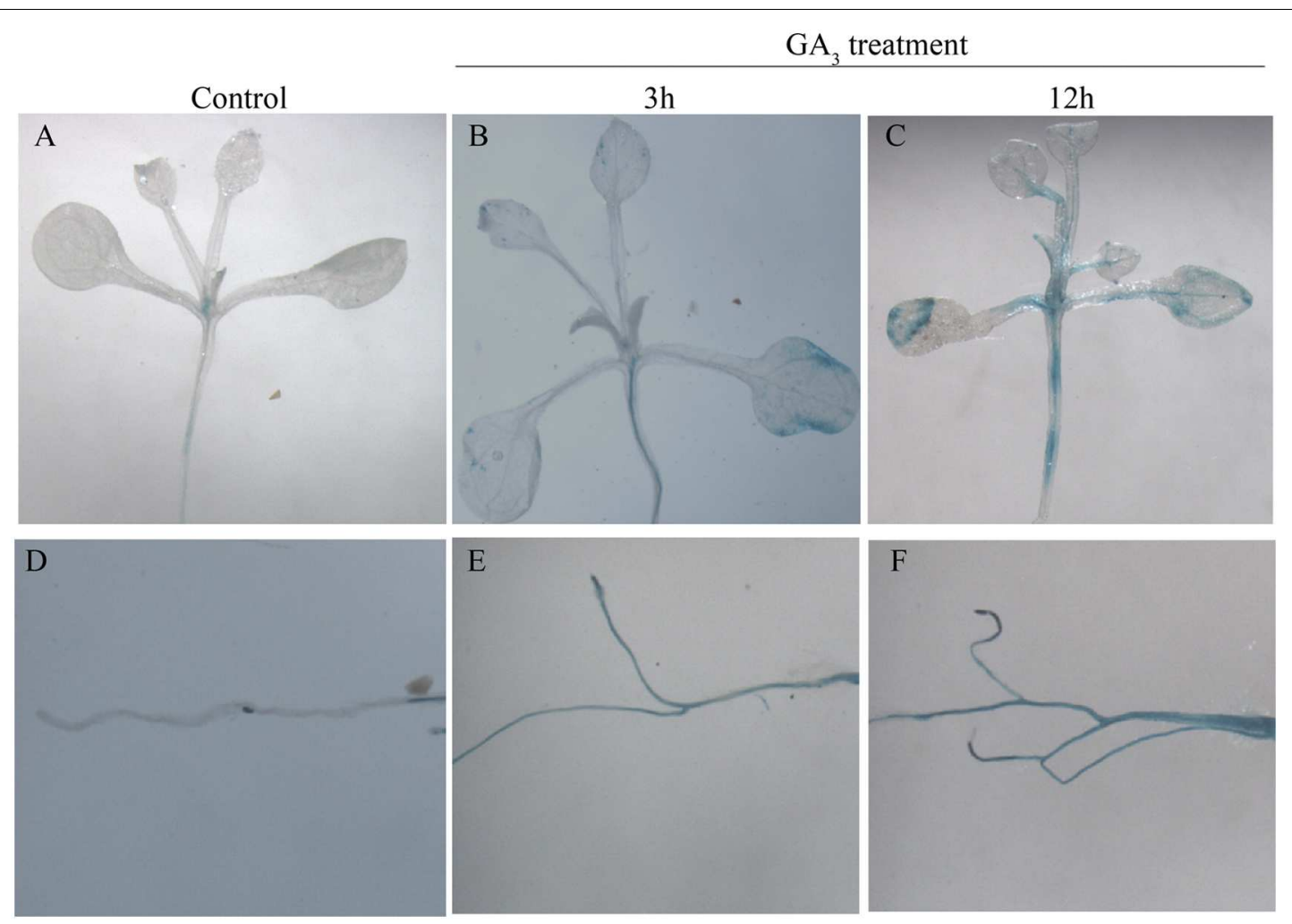

FIGURE 4 | $\beta$-glucuronidase activity analysis in ProGhMPK11::GUS plants in response to $\mathrm{GA}_{3}$. (A,D) No treatment. (B,E) Treated with $\mathrm{GA} 3$ for $3 \mathrm{~h}$. (C,F) Treated with $\mathrm{GA}_{3}$ for $12 \mathrm{~h}$.

A

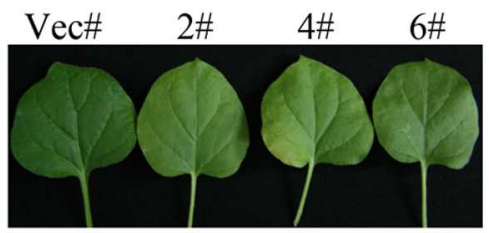

C

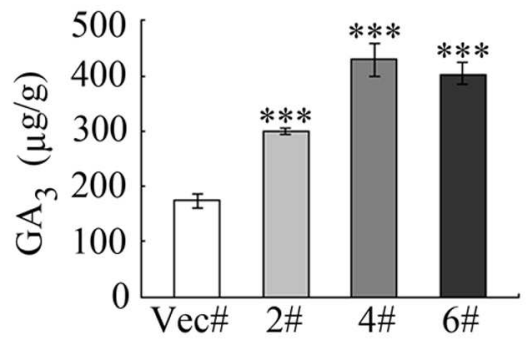

B

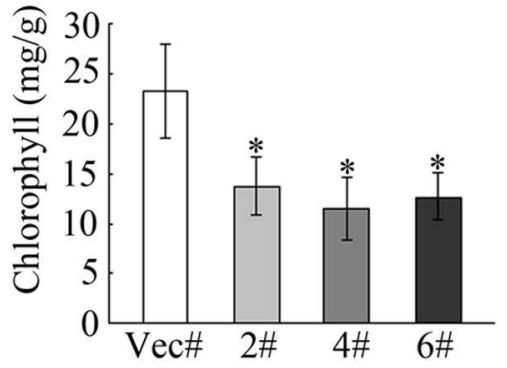

D

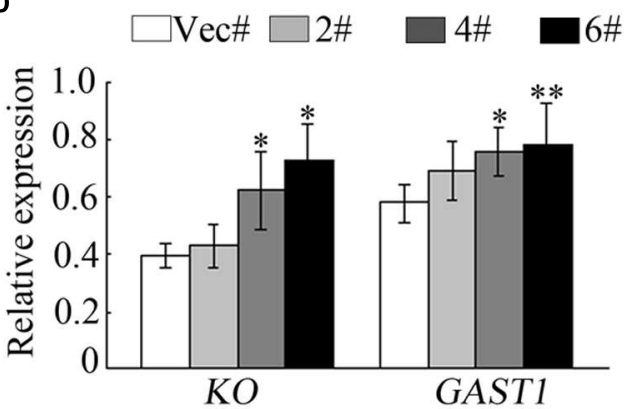

FIGURE 5 | Overexpression of GhMPK11 influences the chlorophyll content. (A) Detached leaves from 8-week-old OE and control plants. (B) The chlorophyll contents of leaves detached from OE and control plants. (C) The $\mathrm{GA}_{3}$ contents in $\mathrm{OE}$ and control plant leaves. (D) GA-related genes expression was detected by qRT-PCR. The data are the means \pm SD from three independent experiments. The asterisks indicate statistically significant differences between the transgenic and control plants $\left({ }^{*} P<0.05 ;{ }^{* *} P<0.01 ;{ }^{* * *} P<0.001\right.$, Student's $t$-test). 

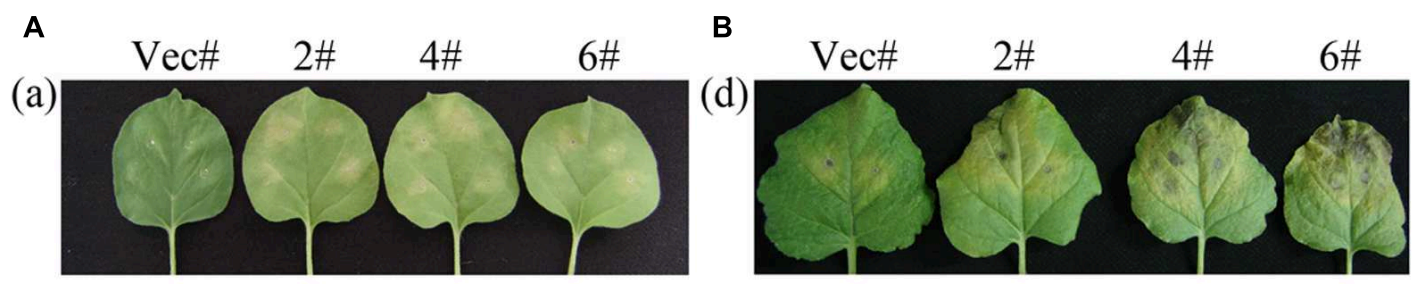

(b)

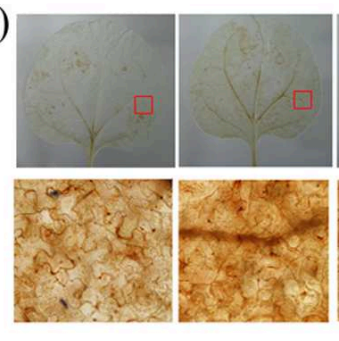

(c)
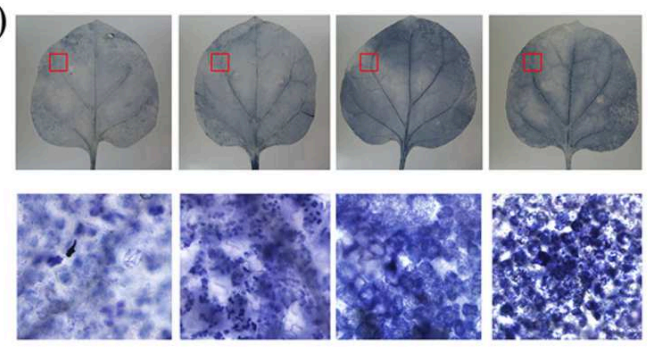

R.solanacearum treatment

C

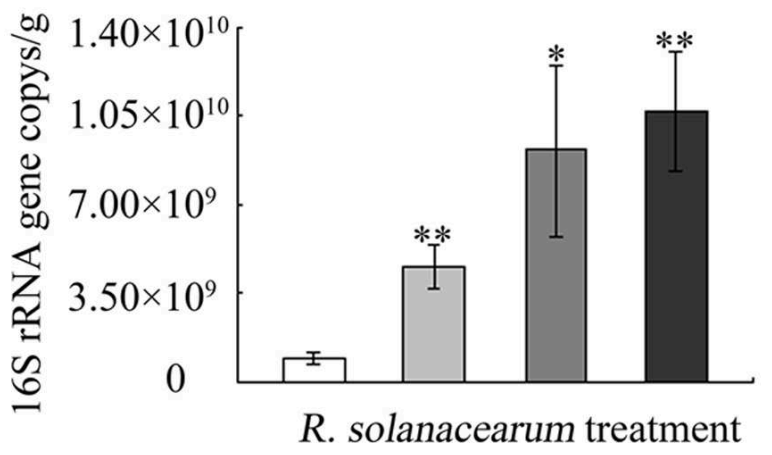

(e)

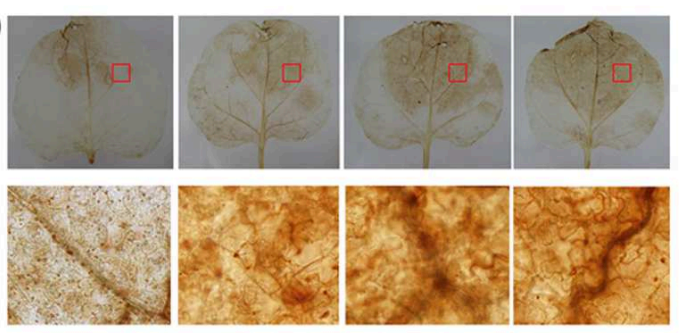

(f)

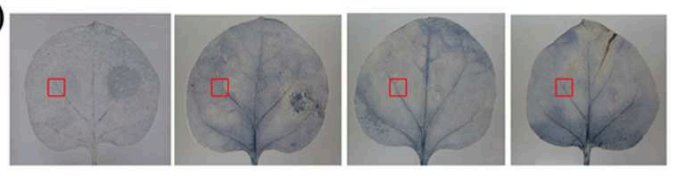

D

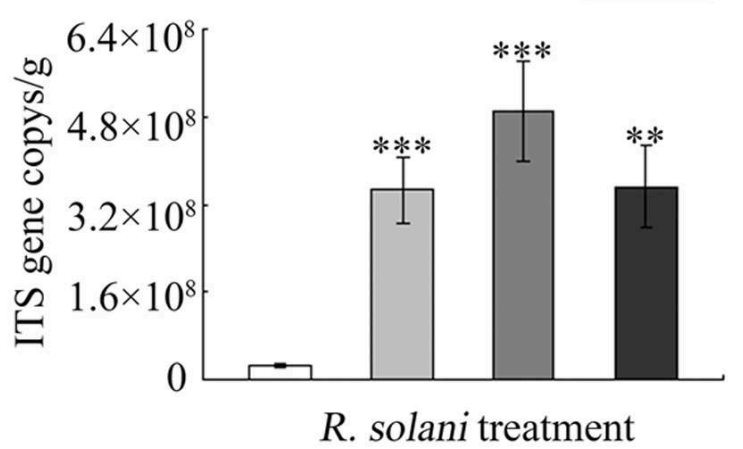

FIGURE 6 | GhMPK11 Overexpression influences the diseases responses of plants. (A) Leaves infiltrated with $R$. solanacearum and $R$. solani (B). The levels of $\mathrm{H}_{2} \mathrm{O}_{2}$ and $\mathrm{O}_{2}^{-}$in leaves were determined by DAB (a) and NBT (b) staining, respectively. (C,D) Pathogen accumulation after 6 days cultivation determined by qRT-PCR. Data are the mean \pm SD from three independent experiments. The asterisks indicate statistically significant differences between the transgenic and control plants $\left({ }^{*} P<0.05 ;{ }^{* *} P<0.01 ;{ }^{* * *} P<0.001\right.$, Student's $t$-test).

showed decreased resistance to the pathogens $R$. solanacearum and $R$. solani; this decreased resistance was verified by the larger necrotic lesions and enhanced pathogen growth observed in infiltrated transgenic plants compared to infiltrate control plants.

Multiple alignments and phylogenetic analyses based on MAPK proteins revealed that GhMPK11 and other MAPK members have a similar protein structure; these analyses confirmed that GhMPK11 encodes a MAPK. Glory and Murphy
(2007) demonstrated that subcellular localization might indicate how a gene interacts with transcription factors to function, offer valuable clues to uncovering its functions, and help understand the complicated pathways that regulate biological processes at the cellular level. GhMPK11 localized to the nucleus, indicating that it might function with transcription factors. In addition, the observed expression pattern of GhMPK11 in response to $\mathrm{GA}_{3}$, as well as the results of promoter analysis and GUS activity analysis, indicated that 

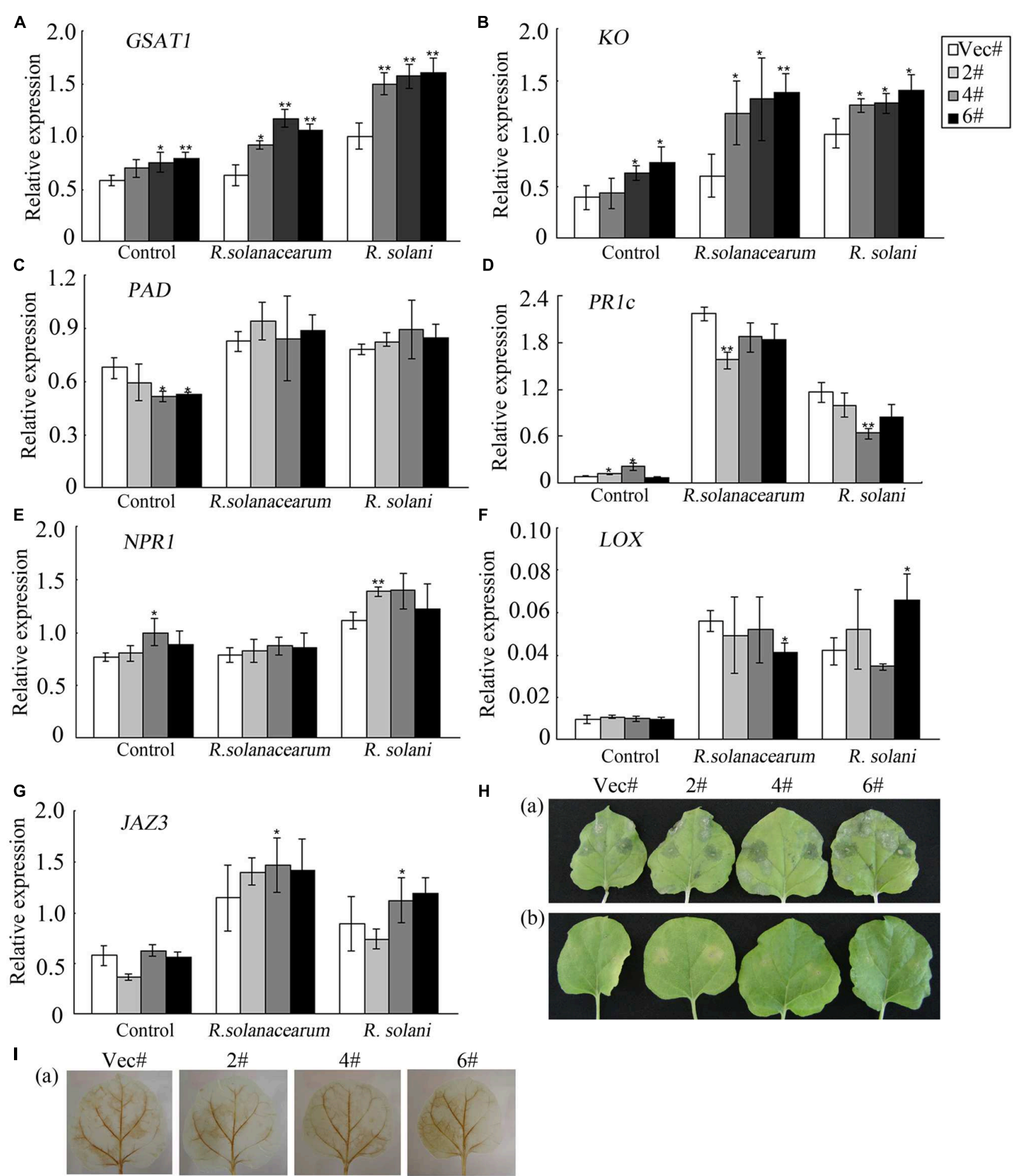

H

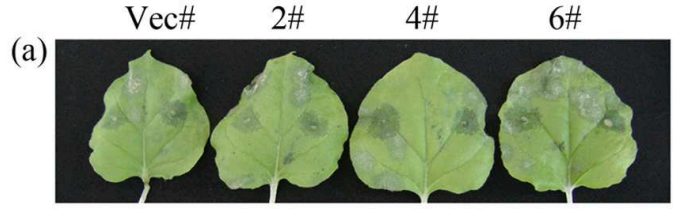

(b)

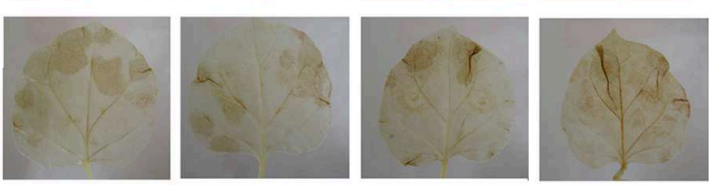

(b)

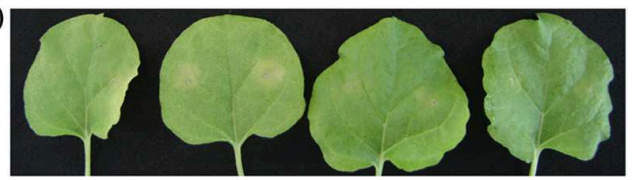

FIGURE 7 | Expression analysis of hormone-related genes and diseases responses of plants under exogenous $\mathrm{GA}_{3}$ treatment. (A-G) The expression levels of the GA-related genes GAST1 and KO; the SA-related genes PAD, PR1C, and NPR1; and the JA-related genes $L O X$ and JAZ3 were detected by qRT-PCR. (H) (a) Leaves treated with $R$. solani and $50 \mathrm{mM} \mathrm{GA}_{3}$ and (b) leaves treated with $R$. solani. (l) DAB staining of leaves shown in (H). The data are the means $\pm \mathrm{SD}$ from three independent experiments. The asterisks indicate statistically significant differences between the transgenic and control plants $(* P<0.05$; $* * P<0.01$, Student's t test). 

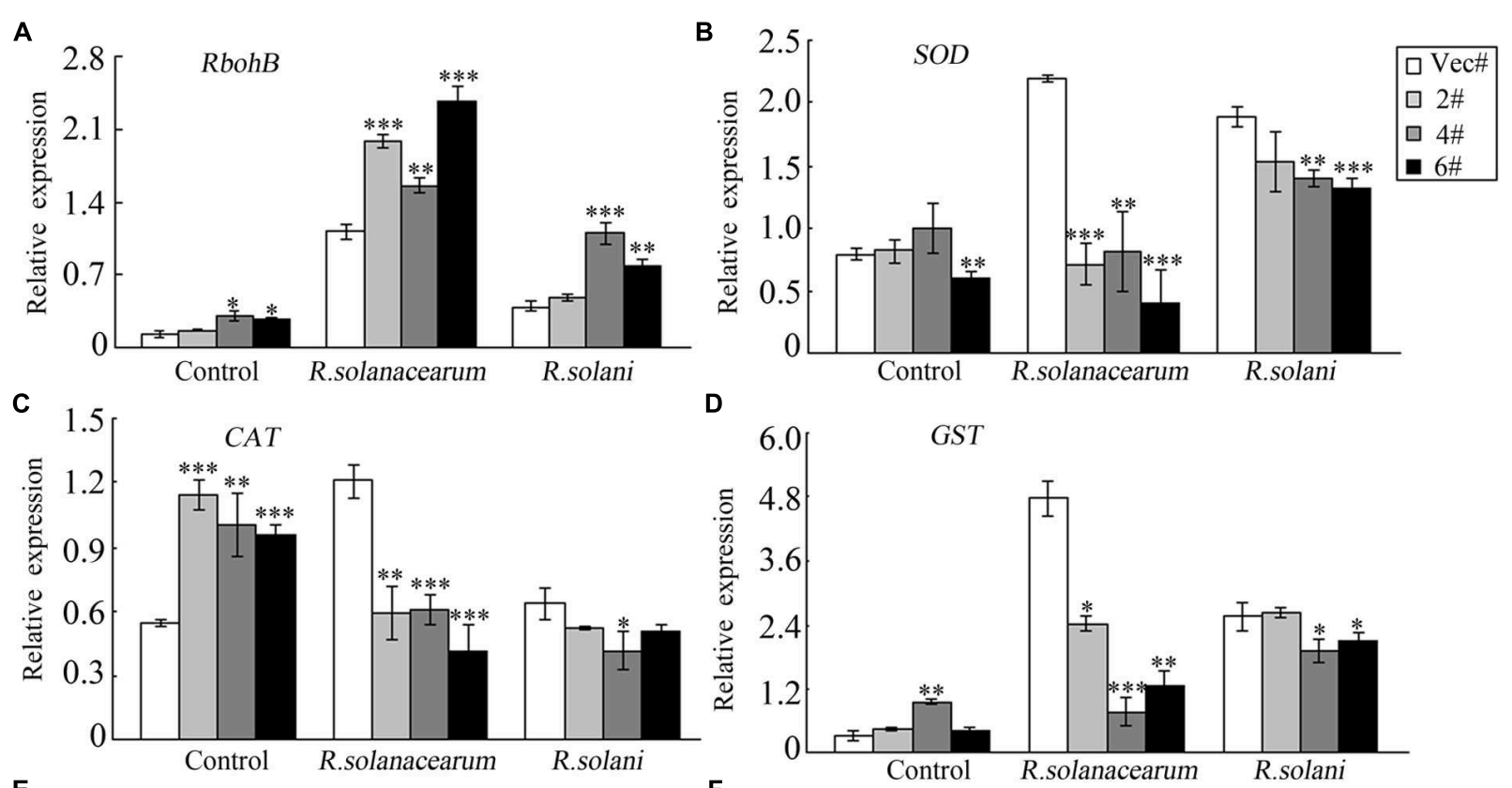

D. 6 GT

E
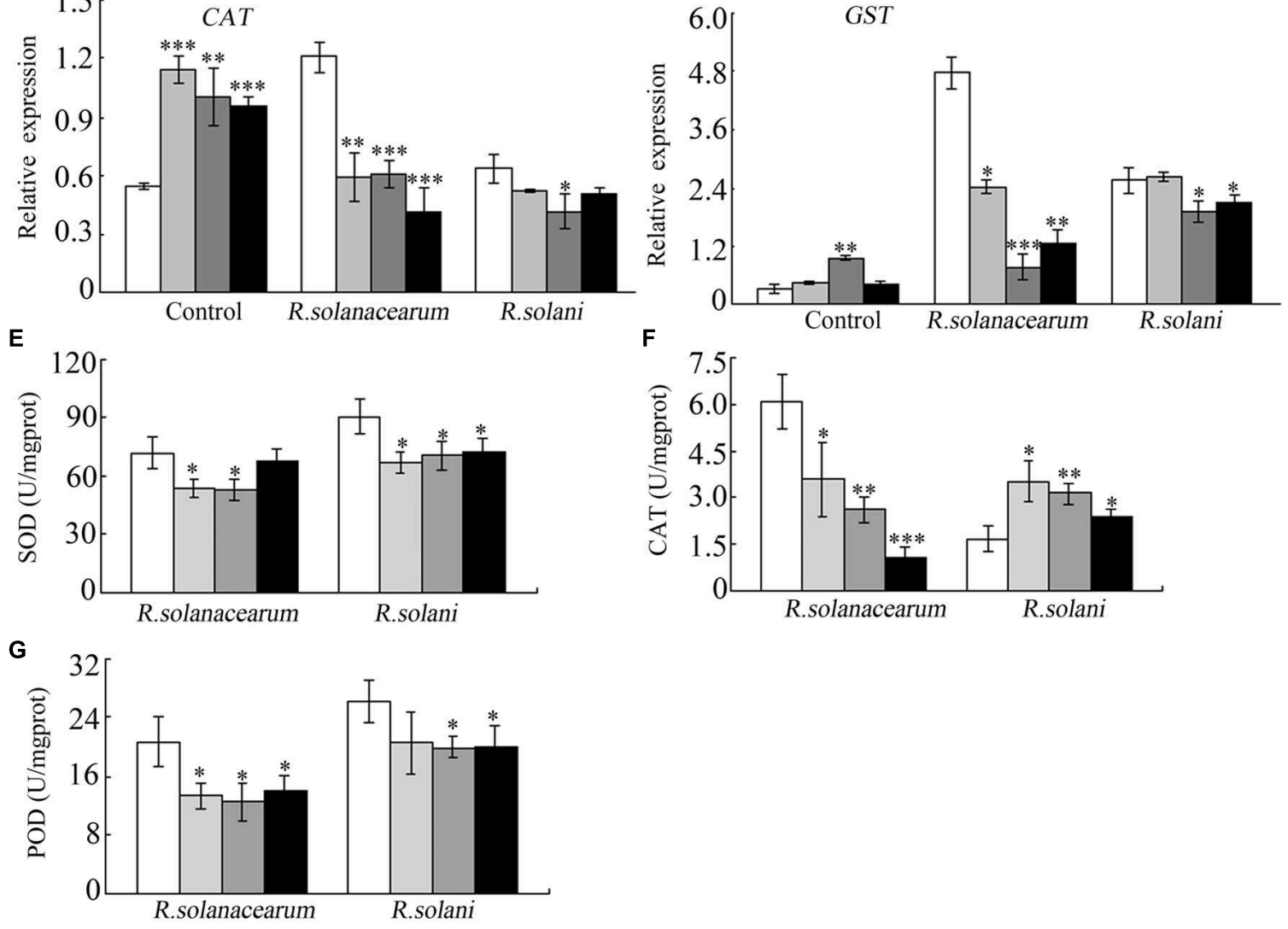

FIGURE 8 | Relative expression levels and enzymes activities of defense-related genes following diseases infections. The expression levels of $R b o h B$ (A), SOD (B), CAT (C) and GST (D) and the total activities of the antioxidant enzymes SOD (E), CAT (F) and POD (G) in tobacco plants at 4 days after infiltration with $R$. solanacearum or $R$. solani. The data are the means $\pm \mathrm{SD}$ from three independent experiments. The asterisks indicate statistically significant differences between the transgenic and control plants $\left({ }^{*} P<0.05 ;{ }^{* *} P<0.01 ;{ }^{* *} P<0.001\right.$, Student's $t$-test).

GhMPK11 might be involved in the GA signaling pathway (Figures 1-4).

To deeply investigate the biological function of GhMPK11, 35 s::GhMPK11 transgenic plants and $35 \mathrm{~s}$ vector control plants were obtained. During the process of transgenic plants growth, an interesting leaf color phenotype was observed. GA is known to have a negative influence on chlorophyll levels in tomato plants (Nir et al., 2014), and compared with wild-type (WT) plants, GA-deficient mutants have darker green leaves (Koornneef and van der Veen, 1980; Koornneef et al., 1985; Peng and Harberd, 1997). Furthermore, GA-deficient plants have higher levels of bioactive GAs than do WT plants (Talon et al., 1990;
Peng et al., 1999). Considering these previous studies and our experimental results, we hypothesized that light green leaves were probably caused by the altered GA content in these plants. The higher $\mathrm{GA}_{3}$ content and GA-related gene (KO, GAST1) expression levels observed in OE plants supported this hypothesis (Figure 5). The transcriptional suppression of $\mathrm{KO}$ has been shown to be responsible for decreased GA content (Fukazawa et al., 2000). GAST1 is a GA-induced gene, and a higher transcript level of this gene correlates with higher $\mathrm{GA}_{3}$ content (Shi and Olszewski, 1998). These findings suggested that GhMPK11 could alter $\mathrm{GA}_{3}$ content by regulating GA-related genes. 

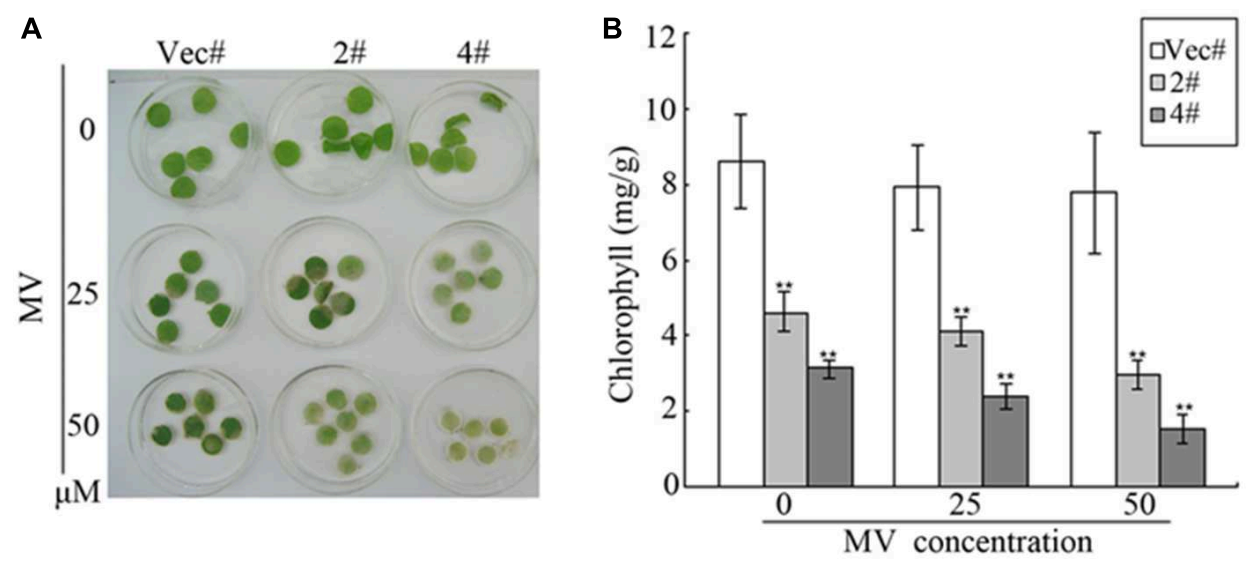

FIGURE 9 | Oxidative analysis of GhMPK11. (A) Leaf disks from control and OE plants soaked in MV solution for $72 \mathrm{~h}$. (B) Relative chlorophyll content after MV treatment. The data are the means \pm SD from three independent experiments. The asterisks indicate statistically significant differences between the transgenic and control plants ${ }^{* *} P<0.01$, Student's $t$-test).

Except enhanced expression of GhMPK11 in response to $\mathrm{GA}_{3}$, strong induction of GhMPK11 expression by pathogens was also detected. This expression pattern is consistent with the expression pattern of AtMPK11 in response to PAMPs (Eschen-Lippold et al., 2012), which suggests that GhMPK11 might function in defense responses. Figure 6 showed that GhMPK11 overexpression could reduce pathogen resistance and enhance pathogen growth. The enhanced susceptibility of GhMPK11 transgenic plants to $R$. solanacearum was consistent with a previous study of MPK4 that demonstrated that an mpk4 mutant exhibited enhanced resistance to Pseudomonas syringae pv. tomato DC3000, a Gram-negative plant pathogenic bacterium (Petersen et al., 2000). Although SA and JA are well-established phytohormones that are involved in disease responses (Yang D.L. et al., 2008), emerging evidence has indicated a relationship between GAs and pathogen infection (Qin et al., 2012). Researchers have found that GAs are actively involved in plant immunity and development (Bari and Jones, 2009; Grant and Jones, 2009); however, the underlying mechanism has been only partially elucidated. To determine which pathway was associated with the enhanced susceptibility of transgenic plants, the expression levels of genes related to $\mathrm{SA}, \mathrm{JA}$ and GA signaling were detected. Significant changes in the expression levels of GA-related genes and slight changes in the expression levels of SAor JA-related genes indicate that the enhanced susceptibility of transgenic plants to diseases might correlate with the GA signaling pathway. To confirm this result, plants were treated with exogenous $\mathrm{GA}_{3}$ while being simultaneously infiltrated with $R$. solani. $\mathrm{OE}$ and control leaves displayed enhanced susceptibility and the same phenotype upon $R$. solani infiltration (Figure 7). Taken together, these results suggest that exogenous $\mathrm{GA}_{3}$ can reduce the influence of endogenous $\mathrm{GA}_{3}$ in transgenic plants on disease responses and that GhMPK11 overexpression can enhance plant susceptibility to pathogen infiltration through the GA signaling pathway. These findings are consistent with the results of a study that found that GA-overproducing eui rice appears more susceptible to bacterial and fungal pathogens in the field (Yang D.L. et al., 2008).

A burst of ROS is a common feature of defense responses (Apel and Hirt, 2004; Jones and Dangl, 2006), and plants have developed intricate pathways to fight various environmental stresses by producing more ROS (Coupe et al., 2006). Furthermore, ROS accumulation has been shown to have a negative effect on resistance to necrotrophic pathogens (Yoshioka et al., 2009). In this study, R. solanacearum and $R$. solani, which are both necrotrophic pathogens, were used to treat plants (Geraats et al., 2003; Van Loon et al., 2006; Molla et al., 2013; Byth-Illing and Bornman, 2014). Therefore, after pathogen treatment, the accumulation of $\mathrm{H}_{2} \mathrm{O}_{2}$ and $\mathrm{O}_{2}^{-}$increased greatly (Figure 6). To further determine the mechanism of ROS accumulation, ROS-related genes were detected. A previous study showed that down-regulation of PvRbohB can decrease $\mathrm{O}_{2}^{-}$and $\mathrm{H}_{2} \mathrm{O}_{2}$ production in P. vulgaris roots (Montiel et al., 2012); conversely, increased expression levels of RbohB will lead to more ROS. In addition, the decreased expression level and activity of ROS detoxification enzymes also contributed to ROS accumulation (Figure 8). The levels of ROS detoxification enzymes can be regulated by the $\mathrm{SCF}^{S L Y 1 / G I D 2}$ complex through the GA signaling pathway (Grant and Jones, 2009). Thus, the decreased tolerance of transgenic plants to MV treatment may be associated with elevated ROS levels (Figure 9).

Considering these findings, we conclude that the enhanced susceptibility of transgenic plants to pathogen infiltration is a result of enhanced ROS accumulation, which is regulated by GhMPK11 through the GA signaling pathway. However, although the influence of GhMPK11 on pathogen resistance was studied here, the comprehensive regulatory mechanism of the defense responses to pathogen infiltration in cotton requires further investigation. 


\section{AUTHOR CONTRIBUTIONS}

XG designed the experiments. FW performed the experiments and analyzed the results with contributions from CW, YY, and HJ. All authors read and approved the final manuscript.

\section{ACKNOWLEDGMENTS}

This work was financially supported by the National Natural Science Foundation of China [Grant Number 31171837; 31471424].

\section{REFERENCES}

Achard, P., Cheng, H., De Grauwe, L., Decat, J., Schoutteten, H., Moritz, T., et al. (2006). Integration of plant responses to environmentally activated phytohormonal signals. Science 311, 91-94. doi: 10.1126/science.1118642

Adie, B. A., Perez-Perez, J., Perez-Perez, M. M., Godoy, M., Sanchez-Serrano, J. J., Schmelz, E. A., et al. (2007). ABA is an essential signal for plant resistance to pathogens affecting JA biosynthesis and the activation of defenses in Arabidopsis. Plant Cell 19, 1665-1681. doi: 10.1105/tpc.106.048041

Apel, K., and Hirt, H. (2004). Reactive oxygen species, metabolism, oxidative stress, and signal transduction. Annu. Rev. Plant Biol. 55, 373-399. doi: 10.1146/annurev.arplant.55.031903.141701

Bari, R., and Jones, J. D. (2009). Role of plant hormones in plant defence responses. Plant Mol. Biol. 69, 473-488. doi: 10.1007/s11103-008-9435-0

Brader, G., Djamei, A., Teige, M., Palva, E. T., and Hirt, H. (2007). The MAP kinase kinase MKK2 affects disease resistance in Arabidopsis. Mol. Plant Microbe Interact. 20, 589-596. doi: 10.1094/MPMI-20-5-0589

Brodersen, P., Petersen, M., Nielsen, H. B., Zhu, S., Newman, M. A., Shokat, K. M., et al. (2006). Arabidopsis MAP kinase 4 regulates salicylic acid- and jasmonic acid/ethylene-dependent responses via EDS1 and PAD4. Plant J. 47, 532-546. doi: 10.1111/j.1365-313X.2006.02806.x

Byth-Illing, H. A., and Bornman, L. (2014). Heat shock, with recovery, promotes protection of Nicotiana tabacum during subsequent exposure to Ralstonia solanacearum. Cell Stress Chaperones 19, 193-203. doi: 10.1007/s12192-0130445-8

Chen, Z. J., Scheffler, B. E., Dennis, E., Triplett, B. A., Zhang, T., Guo, W., et al. (2007). Toward sequencing cotton (Gossypium) genomes. Plant Physiol. 145, 1303-1310. doi: 10.1104/pp.107.107672

Colebrook, E. H., Thomas, S. G., Phillips, A. L., and Hedden, P. (2014). The role of gibberellin signalling in plant responses to abiotic stress. J. Exp. Biol. 217, 67-75. doi: $10.1242 /$ jeb.089938

Cosio, C., and Dunand, C. (2009). Specific functions of individual class III peroxidase genes. J. Exp. Biol. 60, 391-408. doi: 10.1093/jxb/ern318

Coupe, S. A., Palmer, B. G., Lake, J. A., Overy, S. A., Oxborough, K., Woodward, F. I., et al. (2006). Systemic signaling of environmental cues in Arabidopsis leaves. J. Exp. Biol. 57, 329-341. doi: 10.1093/jxb/erj033

Dóczi, R., Brader, G., Pettkó-Szandtner, A., Rajh, I., Djamei, A., Pitzschke, A., et al. (2007). The Arabidopsis mitogen-activated protein kinase kinase MKK3 is upstream of group C mitogen-activated protein kinases and participates in pathogen signaling. Plant Cell 19, 3266-3279. doi: 10.1105/tpc.106.050039

Eschen-Lippold, L., Bethke, G., Palm-Forster, M. A., Pecher, P., Bauer, N., Glazebrook, J., et al. (2012). MPK11-a fourth elicitor-responsive mitogenactivated protein kinase in Arabidopsis thaliana. Plant Signal. Behav. 7, 12031205. doi: $10.4161 /$ psb. 21323

Fryer, M. J., Ball, L., Oxborough, K., Karpinski, S., Mullineaux, P. M., and Baker, N. R. (2003). Control of ascorbate peroxidase 2 expression by hydrogen peroxide and leaf water status during excess light stress reveals a functional organisation of Arabidopsis leaves. Plant J. 33, 691-705. doi: 10.1046/j.1365313X.2003.01656.x

Fryer, M. J., Oxborough, K., Mullineaux, P. M., and Baker, N. R. (2002). Imaging of photo-oxidative stress responses in leaves. J. Exp. Bot. 53, 1249-1254. doi: 10.1093/jexbot/53.372.1249

\section{SUPPLEMENTARY MATERIAL}

The Supplementary Material for this article can be found online at: http://journal.frontiersin.org/article/10.3389/fpls.2016. 00689

FIGURE S1 | The subcellular localization of GhMPK11 protein in onion epidermal cells. Transiently expression of the 35S-GhMPK11-GFP and 35S-GFP constructs in onion epidermal cells. Green fluorescence was observed using a confocal microscope. Onion cell nuclei were marked by DAPI staining. Bar $=200 \mathrm{~mm}$.

TABLE S1 | Primers used in this study.

Fukazawa, J., Sakai, T., Ishida, S., Yamaguchi, I., Kamiya, Y., and Takahashi, Y. (2000). Repression of shoot growth, a bZIP transcriptional activator, regulates cell elongation by controlling the level of gibberellins. Plant Cell 12, 901-915. doi: 10.1105/tpc.12.6.901

Gallego-Bartolomé, J., Minguet, E. G., Grau-Enguix, F., Abbas, M., Locascio, A., Thomas, S. G., et al. (2012). Molecular mechanism for the interaction between gibberellin and brassinosteroid signaling pathways in Arabidopsis. Proc. Natl. Acad. Sci. U.S.A. 109, 13446-13451. doi: 10.1073/pnas.11199 92109

Gao, M., Liu, J., Bi, D., Zhang, Z., Cheng, F., Chen, S., et al. (2008). MEKK1, MKK1/MKK2 and MPK4 function together in a mitogen-activated protein kinase cascade to regulate innate immunity in plants. Cell Res. 18, 1190-1198. doi: $10.1038 / \mathrm{cr} .2008 .300$

Geraats, B. P., Bakker, P. A., Lawrence, C. B., Achuo, E. A., Höfte, M., and van Loon, L. C. (2003). Ethylene-insensitive tobacco shows differentially altered susceptibility to different pathogens. Phytopathology 93, 813-821. doi: 10.1094/PHYTO.2003.93.7.813

Glory, E., and Murphy, R. F. (2007). Automated subcellular location determination and high-throughput microscopy. Dev. Cell 12, 7-16. doi: 10.1016/j.devcel.2006.12.007

Golldack, D., Li, C., Mohan, H., and Probst, N. (2013). Gibberellins and abscisic acid signal crosstalk, living and developing under unfavorable conditions. Plant Cell Rep. 32, 1007-1016. doi: 10.1007/s00299-013-1409-2

Grant, M. R., and Jones, J. D. G. (2009). Hormone (dis) harmony moulds plant health and disease. Science 324, 750-752. doi: 10.1126/science.1173771

Group, M. A. P. K. (2002). Mitogen-activated protein kinase cascades in plants, a new nomenclature. Trends Plant Sci. 7, 301-308. doi: 10.1016/S13601385(02)02302-6

Grover, C. E., Kim, H., Wing, R. A., Paterson, A. H., and Wendel, J. F. (2004). Incongruent patterns of local and global genome size evolution in cotton. Genome Res. 14, 1474-1482. doi: 10.1101/gr.2673204

Hu, G. H., and Yu, S. X. (2007). Extraction of high-quality total RNA in cotton leaf with improved CTAB method. Cotton Sci. 19, 69-70.

Ichimura, T., Wakamiya-Tsuruta, A., Itagaki, C., Taoka, M., Hayano, T., Natsume, T., et al. (2002). Phosphorylation-dependent interaction of kinesin light chain 2 and the 14-3-3 protein. Biochemistry 41, 5566-5572. doi: 10.1021/bi015946f

Jammes, F., Song, C., Shin, D., Munemasa, S., Takeda, K., Gu, D., et al. (2009). MAP kinases MPK9 and MPK12 are preferentially expressed in guard cells and positively regulate ROS-mediated ABA signaling. Proc. Natl. Acad. Sci. U.S.A. 106, 20520-20525. doi: 10.1073/pnas.0907205106

Jefferson, R. A. (1987). Assaying chimeric genes in plants: the GUS gene fusion system. Plant Mol. Biol. Rep. 5, 387-405. doi: 10.1007/BF02667740

Jonak, C., Okrész, L., Bögre, L., and Hirt, H. (2002). Complexity, cross talk and integration of plant MAP kinase signalling. Curr. Opin. Plant Biol. 5, 415-424. doi: 10.1016/S1369-5266(02)00285-6

Jones, J. D. G., and Dangl, J. L. (2006). The plant immune system. Nature 444, 323-329. doi: 10.1038/nature05286

Koornneef, M., Elgersma, A., Hanhart, C. J., van Loenen-Martinet, E. P., van Rijn, L., and Zeevaart, J. A. D. (1985). A gibberellin-insensitive mutant of Arabidopsis thaliana. Physiol. Plant 65, 33-39. doi: 10.1111/j.13993054.1985.tb02355.x 
Koornneef, M., and van der Veen, J. H. (1980). Induction and analysis of gibberellin sensitive mutants in Arabidopsis thaliana (L.) Heynh. Theor. Appl. Genet. 58, 257-263. doi: 10.1007/BF00265176

Kurepa, J., Smalle, J., Van, M. M., and Inze, D. (1998). Oxidative stress tolerance and longevity in Arabidopsis: the late-flowering mutant gigantea is tolerant to paraquat. Plant J. 14, 759-764. doi: 10.1046/j.1365-313x.1998.00168.x

Li, J., Sima, W., Ouyang, B., Wang, T., Ziaf, K., Luo, Z., et al. (2012). Tomato SIDREB gene restricts leaf expansion and internode elongation by downregulating key genes for gibberellin biosynthesis. J. Exp. Bot. 63, 64076420. doi: 10.1093/jxb/ers295

Li, Y., Zhang, L., Wang, X., Zhang, W., Hao, L., Chu, X., et al. (2013). Cotton GhMPK6a negatively regulates osmotic tolerance and bacterial infection in transgenic Nicotiana benthamiana, and plays a pivotal role in development. FEBS J. 280, 5128-5144. doi: 10.1111/febs.12488

Liu, Y. G., and Chen, Y. (2007). High-efficiency thermal asymmetric interlaced PCR for amplification of unknown flanking sequences. Biotechniques 43, 649650. doi: 10.2144/000112601

Lu, W., Chu, X., Li, Y., Wang, C., and Guo, X. (2013). Cotton GhMKK1 induces the tolerance of salt and drought stress, and mediates defence responses to pathogen infection in transgenic Nicotiana benthamiana. PLoS ONE 8:e68503. doi: 10.1371 /journal.pone. 0068503

Meng, X., and Zhang, S. (2013). MAPK cascades in plant disease resistance signaling. Annu. Rev. Phytopathol. 51, 245-266. doi: 10.1146/annurev-phyto082712-102314

Molla, K. A., Karmakar, S., Chanda, P. K., Ghosh, S., Sarkar, S. N., Datta, S. K., et al. (2013). Rice oxalate oxidase gene driven by green tissue-specific promoter increases tolerance to sheath blight pathogen (Rhizoctonia solani) in transgenic rice. Mol. Plant Pathol. 2013, 910-922. doi: 10.1111/mpp. 12055

Montiel, J., Nava, N., Cárdenas, L., Sánchez-López, R., Arthikala, M. K., Santana, O., et al. (2012). A Phaseolus vulgaris NADPH oxidase gene is required for root infection by Rhizobia. Plant Cell Physiol. 53, 1751-1767. doi: $10.1093 / \mathrm{pcp} / \mathrm{pcs} 120$

Nakashita, H., Yasuda, M., Nitta, T., Asami, T., Fujioka, S., Arai, Y., et al. (2003). Brassinosteroid functions in a broad range of disease resistance in tobacco and rice. Plant J. 33, 887-898. doi: 10.1046/j.1365-313X.2003.01675.x

Nir, I., Moshelion, M., and Weiss, D. (2014). The Arabidopsis gibberellin methyl transferase 1 suppresses gibberellin activity, reduces whole-plant transpiration and promotes drought tolerance in transgenic tomato. Plant Cell Environ. 37, 113-123. doi: 10.1111/pce.12135

Ortiz-Masia, D., Perez-Amador, M. A., Carbonell, P., Aniento, F., Carbonell, J., and Marcote, M. J. (2008). Characterization of PsMPK2, the first C1 subgroup MAP kinase from pea (Pisum sativum L.). Planta 227, 1333-1342. doi: 10.1007/s00425-008-0705-5

Peng, J., and Harberd, N. P. (1997). Transposonassociated somatic gai-loss sectors in Arabidopsis. Plant Sci 130, 181-188. doi: 10.1016/S0168-9452(97) 00216-1

Peng, J., Richards, D. E., Moritz, T., Ca no- Delgado, A., and Harberd, N. P. (1999). Extragenic suppressors of the Arabidopsis gai mutation alter the doseresponse relationship of diverse gibberellin responses. Plant Physiol. 119, 1-10. doi: $10.1104 /$ pp.119.4.1199

Petersen, M., Brodersen, P., Naested, H., Andreasson, E., Lindhart, U., Johansen, B., et al. (2000). Arabidopsis map kinase 4 negatively regulates systemic acquired resistance. Cell 103, 1111-1120. doi: 10.1016/S0092-8674(00)00213-0

Pitzschke, A., Schikora, A., and Hirt, H. (2009). MAPK cascade signalling networks in plant defence. Curr. Opin. Plant Biol. 12, 421-426. doi: 10.1016/j.pbi.2009.06.008

Qin, X., Liu, J. H., Zhao, W., Chen, X., Guo, Z., and Peng, Y. (2012). Gibberellin 20 -oxidase gene, OsGA20ox3 regulates plant stature and disease development in rice. Mol. Plant Microbe Interact. 26, 227-239. doi: 10.1094/MPMI-05-120138-R

Rasche, F., Knapp, D., Kaiser, C., Koranda, M., Kitzler, B., ZechmeisterBoltenstern, S., et al. (2011). Seasonality and resource availability control bacterial and archaeal communities in soils of a temperate beech forest. ISME J. 5, 389-402. doi: 10.1038/ismej.2010.138

Rasmussen, M. W., Roux, M., Petersen, M., and Mundy, J. (2012). MAP Kinase cascades in Arabidopsis innate immunity. Front. Plant Sci. 3:169. doi: $10.3389 /$ fpls.2012.00169
Ren, D., Yang, H., and Zhang, S. (2002). Cell death mediated by MAPK is associated with hydrogen peroxide production in Arabidopsis. J. Biol. Chem. 277, 559-565. doi: 10.1074/jbc.M109495200

Rodriguez, M. C. S., Petersen, M., and Mundy, J. (2010). Mitogen-activated protein kinase signaling in plants. Annu. Rev. Plant Biol. 61, 621-649. doi: 10.1146/annurev-arplant-042809-112252

Šamajová, O., Komis, G., and Šamaj, J. (2013). Emerging topics in the cell biology of mitogen-activated protein kinases. Trends Plant Sci. 18, 140-148. doi: 10.1016/j.tplants.2012.11.004

Shan, D. P., Huang, J. G., Yang, Y. T., Guo, Y. H., Wu, C. A., Yang, G. D., et al. (2007). Cotton GhDREB1 increases plant tolerance to low temperature and is negatively regulated by gibberellic acid. New Phytol. 176, 70-81. doi: 10.1111/j.1469-8137.2007.02160.x

Shi, J., An, H., Zhang, L., Gao, Z., and Guo, X. (2010). GhMPK7, a novel multiple stress-responsive cotton group C MAPK gene, has a role in broad spectrum disease resistance and plant development. Plant Mol. Biol. 74, 1-17. doi: 10.1007/s11103-010-9661-0

Shi, L., and Olszewski, N. E. (1998). Gibberellin and abscisic acid regulate GAST1 expression at the level of transcription. Plant Mol. Biol. 38, 1053-1060. doi: 10.1023/A:1006007315718

Siemens, J., Keller, I., Sarx, J., Kunz, S., Schuller, A., Nagel, W., et al. (2006). Transcriptome analysis of Arabidopsis clubroots indicate a key role for cytokinins in disease development. Mol. Plant Microbe Interact. 19, 480-494. doi: 10.1094/MPMI-19-0480

Sinha, A. K., Jaggi, M., Raghuram, B., and Tuteja, N. (2011). Mitogen-activated protein kinase signaling in plants under abiotic stress. Plant Signal. Behav. 6, 196-203. doi: 10.4161/psb.6.2.14701

Sunilkumar, G., Campbell, L. M., Puckhaber, L., Stipanovic, R. D., and Rathore, K. S. (2006). Engineering cottonseed for use in human nutrition by tissuespecific reduction of toxic gossypol. Proc. Natl. Acad. Sci. U.S.A. 103, 1805418059. doi: 10.1073/pnas. 0605389103

Talon, M., Koornneef, M., and Zeevaart, J. A. D. (1990). Accumulation of C19-gibberellins in the gibberellin-insensitive dwarf mutant gai of Arabidopsis thaliana (L) Heynh. Planta 182, 501-505. doi: 10.1007/BF023 41024

Tanoue, T., Adachi, M., Moriguchi, T., and Nishida, E. (2000). A conserved docking motif in MAP kinases common to substrates, activators and regulators. Nat. Cell Biol. 2, 110-116. doi: 10.1038/35000065

Thordal-Christensen, H., Zhang, Z., Wei, Y., and Collinge, D. B. (1997). Subcellular localization of $\mathrm{H}_{2} \mathrm{O}_{2}$ in plants, $\mathrm{H}_{2} \mathrm{O}_{2}$ accumulation in papillae and hypersensitive response during the barley-powdery mildew interaction. Plant $J$. 11, 1187-1194. doi: 10.1046/j.1365-313X.1997.11061187.x

Van Loon, L. C., Geraats, B. P., and Linthorst, H. J. (2006). Ethylene as a modulator of disease resistance in plants. Trends Plant Sci. 11, 184-191. doi: 10.1016/j.tplants.2006.02.005

Wang, F., Zhang, Y., Yao, P., Guo, X., Li, H., and Xu, B. (2014). Molecular identification and stress response of the apoptosis-inducing factor gene 3 (AccAIF3) from Apis cerana cerana. Apidologie 45, 685-700. doi: 10.1007/s13592-014-0285-2

White, T. J., Bruns, T., Lee, S., and Taylor, J. (1990). "Amplification and direct sequencing of fungal ribosomal RNA genes for phylogenetics," in PCR Protocols: A Guide to Methods and Applications, Chap. 38, eds M. Innis, D. Gelfand, J. Sninsky, and T. White (Orlando, FL: Academic Press), 315-322.

Widmann, C., Gibson, S., Jarpe, M. B., and Johnson, G. L. (1999). Mitogenactivated protein kinase, conservation of a three-kinase module from yeast to human. Physiol. Rev. 79, 143-180.

Willekens, H., Chamnongpol, S., Davey, M., Schraudner, M., Langebartels, C., Van Montagu, M., et al. (1997). Catalase is a sink for $\mathrm{H}_{2} \mathrm{O}_{2}$ and is indispensable for stress defence in C3 plants. EMBO J. 16, 4806-4816. doi: 10.1093/emboj/16.16.4806

Willige, B. C., Isono, E., Richter, R., Zourelidou, M., and Schwechheimer, C. (2011). Gibberellin regulates PIN-FORMED abundance and is required for auxin transport-dependent growth and development in Arabidopsis thaliana. Plant Cell 23, 2184-2195. doi: 10.1105/tpc.111.086355

Xie, K., Chen, J., Wang, Q., and Yang, Y. (2014). Direct phosphorylation and activation of a mitogen-activated protein kinase by a calcium-dependent protein kinase in rice. Plant Cell 26, 3077-3089. doi: 10.1105/tpc.114. 126441 
Xu, J., Yang, K. Y., Yoo, S. J., Liu, Y., Ren, D., and Zhang, S. (2014). Reactive oxygen species in signaling the transcriptional activation of WIPK expression in tobacco. Plant Cell Environ. 37, 1614-1625. doi: 10.1111/pce.12271

Yang, D. L., Li, Q., Deng, Y. W., Lou, Y. G., Wang, M. Y., Zhou, G. X., et al. (2008). Altered disease development in the eui mutants and eui overexpressors indicates that gibberellins negatively regulate rice basal disease resistance. Mol. Plant 1, 528-537. doi: 10.1093/mp/ssn021

Yang, L., Tang, R., Zhu, J., Liu, H., Mueller-Roeber, B., Xia, H., et al. (2008). Enhancement of stress tolerance in transgenic tobacco plants constitutively expressing AtIpk2 $\beta$, an inositol polyphosphate 6-/3-kinase from Arabidopsis thaliana. Plant Mol. Biol 66, 329-343. doi: 10.1007/s11103-007-9267-3

Yoshioka, H., Asai, S., Yoshioka, M., and Kobayashi, M. (2009). Molecular mechanisms of generation for nitric oxide and reactive oxygen species, and role of the radical burst in plant immunity. Mol. Cells 28, 321-329. doi: 10.1007/s10059-009-0156-2

Yu, F., Huaxia, Y., Lu, W., Wu, C., Cao, X., and Guo, X. (2012). GhWRKY15, a member of the WRKY transcription factor family identified from cotton (Gossypium hirsutum L.), is involved in disease resistance and plant development. BMC Plant Biol. 12:144. doi: 10.1186/1471-2229-12-144

Zhang, J., Guo, W., and Zhang, T. (2002). Molecular linkage map of allotetraploid cotton (Gossypium hirsutum L. $\times$ Gossypium barbadense L.) with a haploid population. Theor. Appl. Genet. 105, 1166-1174. doi: 10.1007/s00122-0021100-4

Zhang, J., Zou, D., Li, Y., Sun, X., Wang, N. N., Gong, S. Y., et al. (2014). GhMPK17, a cotton mitogen-activated protein kinase, is involved in plant response to high salinity and osmotic stresses and ABA signaling. PLoS ONE 9:e95642. doi: 10.1371/journal.pone.0095642

Zhang, Z., Li, Q., Li, Z., Staswick, P. E., Wang, M., Zhu, Y., et al. (2007). Dual regulation role of $\mathrm{GH}_{3.5}$ in salicylic acid and auxin signaling during Arabidopsis-Pseudomonas syringae interaction. Plant Physiol. 145, 450-464. doi: $10.1104 /$ pp.107.106021

Conflict of Interest Statement: The authors declare that the research was conducted in the absence of any commercial or financial relationships that could be construed as a potential conflict of interest.

Copyright (c) 2016 Wang, Wang, Yan, Jia and Guo. This is an open-access article distributed under the terms of the Creative Commons Attribution License (CC BY). The use, distribution or reproduction in other forums is permitted, provided the original author(s) or licensor are credited and that the original publication in this journal is cited, in accordance with accepted academic practice. No use, distribution or reproduction is permitted which does not comply with these terms. 